\title{
VERSIONES Y DISTRIBUCIÓN GEOGRÁFICA DEL MITO DE "EL ORIGEN DE LAS MANCHAS DE LA LUNA" EN LA TRADICIÓN ORAL INDOAMERICANA
}

\author{
Enrique Margery Peña
}

\begin{abstract}
RESUMEN
Este artículo describe los motivos y la distribución geográfica de las distintas versiones del mito de "El origen de las manchas de la luna" en Indoamérica. Los motivos se clasifican de acuerdo a su catalogación en el Motif-Index de Stith Thompson.
\end{abstract}

\section{ABSTRACT}

This article describes the motifs and the geographical distribution of differents versions of the myth of The origen of Moon's spots in Indoamerica. These motifs are classified according to Stith Thompson's Motif-Index.

\section{Preliminares}

Entre los numerosos mitos lunares existentes en Indoamérica, el que al parecer presenta una mayor frecuencia es el de "El origen de las manchas de la luna".

De manera consecuente con la metodología que hemos seguido en anteriores descripciones comparativas de mitos indoamericanos, hemos identificado y catalogado los motivos contenidos en las distintas versiones de acuerdo con el Motif-Index de Stith Thompson, señalando aquí al respecto que el análisis de este mito constituye uno de los casos en que esta obra del folklorista norteamericano ofrece no pocos inconvenientes para la catalogación de los motivos contenidos en este género de relatos de la tradición oral de nuestro Continente.

En este sentido, cabe hacer notar que el mito en referencia corresponde al motivo A 751 del Motif-Index, cuyo contenido se enuncia como "Man in the moon" ("Hombre en la luna'), especificándose a continuación: "A man is said to be seen in the moon. Various explanations are given as to how he came to be there" ('Se dice que en la luna se ve un hombre. Se dan varias explicaciones acerca de por qué él llegó a estar allî').

La mención del "hombre en la luna" como elemento subordinante de la mayor parte de los motivos subsecuentes en el Motif-Index, lleva a formulaciones contradictorias, tal como ocurre con los motivos A 751.2 Man in the moon a rabbit (hare, other animal) ('El 
hombre en la luna [es] un conejo (liebre u otro animal)') o A 751.3.1 Man in the moon a frog which has jumped into person's face and remain there ('El hombre en la luna es una rana que ha saltado al rostro de una persona y permanece allí').

Las dificultades que plantea el cotejo de los contenidos de las versiones indoamericanas de este mito -en las que la figura del hombre presenta una escasa frecuencia- con los correspondientes motivos del Motif-Index, nos han conducido en determinadas ocasiones a omitir la referencia a la figura del hombre, considerando únicamente la explicación sobre el origen de las manchas de la luna aportadas por las versiones pertinentes. En estos casos, los enunciados de tales motivos van seguidos por la notación "+ o ++", lo cual, de acuerdo con el criterio aplicado por Johannes Wilbert y Karin Simoneau ${ }^{1}$, significa que el enunciado del mito o motivo mítico de que se trata, no se ajusta de manera absoluta al correspondiente motivo del Motif-Index.

Por otra parte, determinados motivos como los que atribuyen las manchas de la luna a quemaduras, golpes, huellas de una mano sucia o de dedos chamuscados, o bien a sangre, barro o mocos lanzados a su cuerpo, se han incluido en el motivo A 751.11 Otras marcas en la luna.

Finalmente, cabe señalar que en pro de la sistematicidad de nuestra exposición, no hemos seguido el orden en el que los motivos comprendidos entre A 751 y A 751.11 se disponen en la obra de Thompson, haciéndolo en cambio de acuerdo con la frecuencia que las variantes del mito presentan en el corpus de versiones que hemos registrado.

\section{Las manchas de la luna son rasguños o pintura (A $751.5++)$}

Es en este motivo, especialmente en las versiones que explican las manchas de la luna como pintura, donde se agrupa la mayor cantidad de textos correspondientes al mito. Dado, no obstante, el hecho de que las versiones basadas en rasguños presentan contenidos muy distintos con respecto a aquellas que lo hacen en relación con la pintura, comenzaremos nuestras descripciones en el orden prefijado por el enunciado del motivo.

\subsection{Las manchas de la luna son rasguños}

En lo relacionado con este contenido, obran en nuestro conocimiento tres versiones: una que procede del Área del $\mathrm{Chaco}^{2}$, correspondiente a un relato mataco (Métraux 1939/1973: 21), y dos procedentes del Área Pampeana, a saber, un relato puelche (Lehmann-Nitsche 1919: 183-184) y otro tehuelche, recogido por R. Casamiquela (Wilbert y Simoneau 1984b: 19).

Se trata de versiones que, no obstante, muestran diferentes contenidos. Así, en el relato mataco (A 736.6 Sol y Luna como amigos), Sol, transformándose en pato logra cazar con éxito muchas de estas aves. Disgustado por esto, Luna intenta hacer lo mismo. Sin embargo, desconfiados, los patos defecan, obligando con ello a Luna a hacer lo mismo. Los excrementos de éste huelen tan mal que los patos lo descubren, tras lo cual lo rasguñan hasta desollar su cuerpo.

A su vez, el relato puelche (A 736.3.2 Sol y Luna hermanos varones; Sol inteligente y Luna estúpido) refiere que el Sol pierde a un hijo que es robado por dos pájaros negros. Tras 
fallar, junto con Luna, en su intento por coger a los pájaros para extraerles los huesos de su hijo y poder así rehacerlo, el Sol reúne a los animales para determinar la extensión tanto del día y de la noche como del verano y del invierno. El cierre del relato, que contiene la referencia al mito aquí estudiado, es el siguiente:

\footnotetext{
"Entonces el sol dijo: "Yo me voy al cielo", y al hermano menor, la luna, dijo: "¡Vos también vas al cielo! Andá a tal parte y vas a pegar un solo ${ }^{3}$ grito, que van a salir de sus cuevas los piches [armadillos] a patadas"; así dijo el sol a la luna: "un solo grito vas a gritar y van a salir los piches de sus cuevas". Pero la luna pegó dos gritos y salieron demasiados piches y le rasguñaron la cara; y por eso tiene la luna la cara rasguñada".
}

Finalmente, el relato tehuelche (A 736.1 Sol y Luna como hombre y mujer) refiere la disputa entre ambas entidades por subir al cielo y alumbrar el mundo. Tras la lucha, ganada por el Sol, la Luna queda con múltiples rasguños en su cara.

\subsection{Las manchas de la luna son de pintura}

En relación con el motivo A 751.5 ++, las versiones que explican el origen de las manchas de la luna como marcas de pintura son sin duda las más frecuentes tanto en Sudamérica como en la América del Norte.

El desarrollo narrativo más reiterado de este componente del motivo es el siguiente: Al lecho (o hamaca) de una muchacha llega en las noches un misterioso visitante para copular con ella. Deseosa de saber quién es su amante nocturno, la muchacha se provee de una pintura indeleble hecha de vegetales y, cierta noche, le mancha con ella la cara. A la mañana siguiente, al ver la pintura en el rostro de su propio hermano, la muchacha descubre que aquel es el visitante nocturno. Avergonzado y repudiado por el incesto cometido, el hermano huye al cielo transformándose en la luna, pero conservando en su cara las manchas de pintura por las que había sido descubierto.

Este desarrollo narrativo implica la concurrencia de dos motivos, clasificados respectivamente en el Motif-Index como T 415 Incesto hermano-hermana, y H 58 Relato de las marcas de la mano. El amante clandestino es identificado por las marcas de pintura que la mujer deja en su piel.

Este desarrollo narrativo muestra, no obstante, una divergencia relevante entre las versiones procedentes de las áreas culturales sudamericanas con respecto a las originadas en la América del Norte, en lo que se refiere a la actancia femenina.

Así, en lo que corresponde a Sudamérica, incluida en ella el Área Intermedia, la muchacha seducida no posee otra condición que la de ser hermana de Luna, en tanto que en las versiones recogidas en América del Norte, ella es la que a la postre se transforma en el Sol.

A continuación, en lo que concierne a Sudamérica, citaremos los pasajes pertinentes de tres versiones procedentes de distintas áreas culturales de este subcontinente. Se trata de un texto cuna (a) (Mac Chapin 1989: 33-35), perteneciente al Área Intermedia; un texto yabarana (b) (Armellada y Bentivenga 1974/1991: 294-295), correspondiente al Área Caribeña, y un texto cubeo (c) (Correa 1997: 65-66), correspondiente al Área Amazónica:

(a) "En poco tiempo, Olotwaligipileler comenzó a sentir el natural deseo sexual por una mujer, pero dado que desdeñaba la idea de mezclar su sangre con la de aquellos seres de raza inferior... comenzó a meterse secretamente en la hamaca de su hermana mientras ésta dormía. 
Cada mañana ella se despertaba con la certeza de haber sido violada, pero no podía imaginar quién podría ser el misterioso amante. Entonces dijo a una de sus criadas, Ologugiliyai (piojo), que la despertara cuando llegara el hombre. Él llegó, pero Ologugiliyai no cumplió su tarea. A la noche siguiente pidió a otra criada, Oloninirdili (garrapata), que la despertara, pero ella también fracasó... Pero Magiryai no se dio por vencida y dijo a Oloichoryai (pequeño bicho de la arena) que la despertara cuando apareciera el hombre - y ella también falló. Finalmente, tomó a otra criada, Oloardilisop (otro bichito de la arena que pica los pies), y le dio las mismas instrucciones. Cuando apareció el hombre, Oloardilisop picó duro a Magiryai y la despertó. Alcanzando por debajo de la hamaca con cuidado, metió los dedos en una calabaza de sabdur (jagua) y dio una bofetada en la cara del hombre. Éste dio un salto y se fue huyendo en la oscuridad... entonces Magiryai secó todos los ríos y lagos del mundo para que el culpable no pudiera lavar las manchas negras de su cara. A la mañana siguiente, Magiryai preparó bebida para toda la gente de la región, y al llegar ellos se quedó observando quién tenía la cara manchada, pero no pudo encontrar al amante secreto... Al regresar a su casa descubrió al hermano aún dormido con una manta cubriéndole la cara. Le preguntó que porqué no se levantaba y él contestó que tenía fiebre... Ella fue a ayudarle y acercándose le quitó la manta y vio la cara manchada de negro. Lleno de rabia, él recogió todas sus cosas y se fue corriendo al monte. Magiryai salió tras él, diciendo que no le importaba, que podrían vivir juntos como marido y mujer, pero [él] no la oyó y en poco tiempo desapareció en la selva... [Magiryai] caminó por meses hasta que una tarde se halló al pie de una alta montaña. En la cumbre divisó a su hermano que portaba una luz brillante que le envolvía y antes de que ella pudiera abrirse paso entre la tupida selva, éste fue ascendiendo al cielo. Así Ololwaligipileler se convirtió en Luna, y las manchas negras de su cara aún se pueden distinguir cuando traza su curso a través de los cielos".

(b) "Una muchacha fue requerida en plena noche por un joven misterioso. A la mañana siguiente, la muchacha quiso conocer a su amante, pero éste habíase ya fugado. Para la noche siguiente, pintó la muchacha sus senos con onoto, esperando que al día siguiente reconociese al joven por las manchas rojas de la cara. Pero él quitóse las manchas con el aceite de la palma seje, y la muchacha no pudo dar con él. Ella volvió a pintar sus senos con una pintura más fuerte e imborrable: la pintura negra del "matapalo"... A la mañana siguiente vio las manchas negras en la cara de su propio hermano. Por miedo al castigo espantoso que a esto seguiría, el incestuoso hermano huyó hasta los confines de la tierra, donde se transformó en la Luna. Las manchas negras de su cara pueden aún verse en la luna en sus períodos de crecimiento y mengua".

(c) "Los Kuwaiwa eran cuatro hermanos varones que tenían tres hermanas... Una noche, uno de los cuatro hombres fue a la hamaca de una de las hermanas, hizo el amor con ella. La muchacha no sabía cuál de ellos había sido. Esto sucedió muchas veces hasta que ella misma preparó wei y lo dejó cerca de ella para ver quién era el que se metía en su hamaca. Ella estaba acostada cuando llegó el hombre, hicieron el amor, ella le acarició la cara con su mano untada de wei; lo dejó así, él se fue. A la mañana siguiente él se fue al puerto donde se bañaban. Uno de sus hermanos le preguntó: “¿Qué le pasó en la cara?” Él ya se había visto en el agua, pero no había dicho nada por verguienza. Regresó a la casa con la cara manchada; la hermana lo vio: "Seguro él es quien me molesta en las noches". Él... estaba avergonzado; pensaba "¿Qué voy a ser? ¿Qué me voy a volver?"... tuvo una idea: "Me voy a volver Dueño de la Noche”... "Voy a ser una persona que va a vivir dando luz en la noche a la tierra"... Dijo esto y se fue... Él se fue a Jia Dobedo y de ahí mismo vino con esa luz, salió por lo alto alumbrando la tierra...".

Este esquema narrativo, con similares contenidos, se registra en tres versiones de pueblos del Área Caribeña, a saber: arahuaco de Guyana (Lowie 1948: 54), caribe de la Isla Guadalupe (Muñoz de Coronado 1989/1992: 89-94) y guaraúno (Lowie Id.: 54), así como en versiones de cuatro pueblos del Área Amazónica, cuales son los kanamarí (Reesink 1988: 123), kuniba (Lévi-Strauss 1968/1979: 71), záparo (Steward y Métraux 1948: 649), y en dos textos tukuna (v.1 Lévi-Strauss Id.: 26 y v.2 Rodríguez de Montes 1981: 62). A éstas deben sumarse las versiones de siete pueblos también del Área Amazónica que al respecto anota Bierhorst (1988: 27), correspondientes a los barasana ${ }^{4}$, makuna, sharanawa, shipaya, tanimuca, urubú y witoto, más otras dos versiones que incluye este autor y que proceden de los bororo y los tapirapé, pueblos ambos del Área del Este del Brasil. 
Como versiones que por plantear una condición distinta de una o de ambas actancias, se apartan en mayor o menor grado de este esquema, cabe mencionar tres textos procedentes del Área Amazónica y uno del Área del Brasil, en los cuales se involucra al Sol. Así, un relato conibo (AM.) (Steward y Métraux Id.: 595) refiere que la hermana seducida es propiamente el Sol. A su vez, en una versión guaraní (E.BR.) citada por Métraux (1948a: 93), el rostro de Luna es untado con genipa por el Sol, su hermano, con quien tuvo relaciones homosexuales. Por otra parte, la presencia del Sol se da también en una versión andoque (AM.) (Landaburu y Pineda 1984: 45-53), en la que Luna "molesta" a Tortuga-Redonda, su cuñada y mujer del Sol, y en un relato arekuna (AM:), en el que al margen de referir que la muchacha seducida es una de las hijas del Sol, se reemplaza el componente de la pintura por el de la sangre menstrual ${ }^{5}$, tal como se aprecia en el siguiente texto citado por Lévi-Strauss (1968/1979: 247):

"En otro tiempo, Wei y Kapei, el Sol y la Luna, eran inseparables amigos. En aquel tiempo, Kapei tenía faz pura y graciosa. Se enamoró de una de las hijas del Sol y la visitaba noche tras noche. Esto no plugó a Wei, que ordenó a su hija que embadurnara el rostro del amante con sangre menstrual. Desde entonces los astros se volvieron enemigos, la Luna evita al Sol y tiene la cara sucia".

Este último relato arekuna integra, a su vez, un conjunto de versiones que se apartan del ya señalado esquema al no darse en ellas la relación de hermanos entre la muchacha seducida y Luna, su amante nocturno. Al respecto, otros cuatro textos también correspondientes al Área Amazónica manifiestan esta característica. Se trata de textos jívaro (v.1) (Karsten 1935/1989: 591), guarayú (Métraux 1948b: 438), huachipaeri (Califano y Gonzalo 1995: 181-190) y shipibo (v.1). A continuación, citamos esta última versión tal como la refiere Cárdenas Timoteo (1989: 22), con el propósito de evidenciar la permanencia de los elementos básicos del esquema mítico que se da en estas versiones:

"La Luna (un hombre joven) vivía en la tierra, y una noche entró al mosquitero de una muchacha sin haber sido invitado. La próxima noche, la muchacha estuvo lista para recibirlo. Cuando vino, ella lo golpeó con huito en un lado de la cara de modo que pudiera ser identificado al día siguiente. El joven huyó y como el huito no salió de su cara, se fue al cielo (aparentemente por vergüenza) y se convirtió en luna. Todavía está allí y el huito aún no ha desaparecido".

Ya totalmente al margen del esquema narrativo aquí especificado, aunque constituyendo asimismo versiones correspondientes al motivo A 751.5, cabe mencionar otros dos textos también procedentes del Área Amazónica. El primero de ellos es un relato tumupasa (Métraux 1948b: 448) que refiere que las manchas de la luna son de pintura de genipa dejadas en su cara por Venus durante una chichada. El segundo relato es un texto jívaro (v.2) (Stirling 1938: 124) que relata que Nantu (la luna), quien por timidez no respondía a los requerimientos amorosos de Etsa (el sol), aprovechó en una ocasión que éste estaba pintando su rostro con achiote para verse más atractivo, y huyó al cielo, donde se pintó a su vez el cuerpo y la cara con sua para llegar a ser del color de la noche.

En lo que respecta a las versiones originadas en América del Norte, ellas presentan una gran similitud, en lo que se refiere al esquema narrativo básico, con las procedentes de Sudamérica, dado que, al igual que éstas, se estructuran conforme a los motivos T 415 Incesto de hermano-hermana y H 58 Relato de las marcas de la mano. No obstante, y tomando 
como paradigma versiones recogidas en el Área Esquimal (ESK.) ${ }^{6}$, donde este mito muestra una gran difusión, cabe señalar la existencia de al menos seis elementos que las diferencian del común de las aquí referidas versiones sudamericanas. Estos elementos son los siguientes: (i) los hermanos que protagonizan el relato son invariablemente la Luna y el Sol; (ii) el lugar donde se produce la relación sexual es una casa de juegos o de danzas; (iii) el elemento identificador es el hollín; (iv) la muchacha unta con hollín invariablemente la espalda del violador; (v) se introduce un incidente cual es que al reconocer por las marcas a su propio hermano, la muchacha se cercena los pechos y se los arroja a aquel, y (vi) se añade al final un episodio que refiere que tras este último incidente, y provistos de sendas antorchas, Sol huye al cielo perseguida por su hermano, pero al tropezar éste y caer su antorcha en la nieve, su fuego se atenúa (motivo A 759.3 Porqué la luna es pálida).

Un paradigma narrativo de este nuevo esquema lo constituyen dos versiones, ambas recogidas en el siglo diecinueve. La primera, que hemos traducido del inglés, procede del esquimal central (a) (Erdoes y Ortiz 1984: 161-162). En el caso de la segunda, se trata del pasaje pertinente de un relato del esquimal del oeste de Groenlandia (b), editado por Henry Rink (1875/1991: 79-81):

(a) En tiempos pasados, cuando todo comenzaba, un hermano vivía con su hermana en una gran aldea donde había una casa de bailes. En las noches, la casa se alumbraba con lámparas de piedra en las que ardía aceite de foca. Cierta vez que la hermana estaba allí cantando y bailando, un fuerte viento apagó todas las lámparas, y mientras todo estaba a oscuras, un hombre copuló con ella. Ella se resistió, pero él era muy fuerte y estaba demasiado oscuro para ver quien era. Pensando que él podría volver, antes de regresar allí la noche siguiente, ella ennegreció con hollín las palmas de sus manos. De nuevo, una ráfaga de viento apagó todas las lámparas, y otra vez aquel hombre la arrojó de espaldas, se subió sobre ella y la penetró. Sin embargo, mientras esto sucedía, ella untó la espalda del hombre con hollín. Cuando las lámparas se volvieron a encender, ella buscó a alguien con la espalda manchada, y se enfureció al ver que aquel no era otro que su propio hermano. Ella gritó: “ ¡Esas cosas no se hacen! ¡Es inaudito!”. Estaba tan encolerizada que cogió un afilado cuchillo y se cortó sus dos pechos. Lanzándolos a su hermano, le gritó: "“Tanto como pareces gozar de mí, podría gustarte mi cuerpo! ¿Cómetelos!” Ella agarró una antorcha encendida y, enfurecida y como loca, salió corriendo hacia la oscura noche. Su hermano tomó precipitadamente otra antorcha y corrió tras ella, pero tropezó y cayó en la nieve, la cual apagó las llamas de su antorcha, de modo que sólo sus brasas quedaron alumbrando débilmente. Entonces, un fuerte viento los elevó a ambos hermanos hasta el cielo. La muchacha se transformó en el Sol y su hermano en la Luna. Ella permanece tan lejos de él como le es posible. Mientras la luna brilla, ella se oculta, saliendo sólo después de que él se ha ido. Si el hermano no hubiera dejado caer su antorcha en la nieve, la luna sería tan brillante como el sol.

(b) "...Al cabo de un tiempo, la anciana escuchó ruido como de pisadas humanas, y esta vez entró en la casa una mujer bellísima. "¿Quién eres?" -le preguntó la anciana. "En días pasados"- le respondió la extraña- "los jóvenes solíamos reunirnos en mi casa para divertirnos con varios juegos; después, al llegar la noche, las muchachas nos quedábamos fuera de la casa y los chicos se ponían a perseguirnos y cortejarnos, y nunca éramos capaces de distinguirlos en la oscuridad. Una noche, sentí curiosidad por saber qué muchacho me había elegido, así que antes de reunirme con las otras chicas me manché las manos de hollín. Cuando terminamos de jugar, le pasé las manos por la espalda a mi pareja. Le dejé ir y fui la primera en entrar a la casa. Después fueron apareciendo todos los mozos desvestidos, pero durante un rato no pude observar marcas en ninguno de ellos. El último en entrar fue mi hermano, y al momento vi que la parte posterior de su abrigo blanco estaba manchada de hollín. Entonces tomé un cuchillo, lo afilé, me corté los dos pechos y se los entregué diciéndole: "Ya que mi cuerpo parece gustarte, toma esto y cómetelo" y él comenzó a decirme palabras soeces y a perseguirme por la habitación, y mientras corríamos cogió un poco de musgo malo y le prendió fuego; entonces yo me hice con un poco de musgo bueno y lo prendí también. Salió de la habitación corriendo y 
yo tras él, mas, apenas pusimos los pies fuera de la casa, sentimos de pronto cómo algo nos levantaba y nos lanzaba muy alto al aire. Seguimos subiendo hasta que a mi hermano se le apagó el musgo, pero el mío siguió ardiendo, y me convertí en el Sol. Ahora voy camino a las alturas, pues debo dar calor a los huérfanos..."

Tal como lo señalamos, este esquema narrativo se halla ampliamente difundido en la tradición oral de los pueblos de la América del Norte, especialmente en las regiones ártica y noroeste. En este sentido, cabe anotar que Stith Thompson (1929/1967: 273 n.6 y 274 n.8), en lo que corresponde al Área Esquimal, registra su existencia en el esquimal central, así como entre los esquimales del Este de Groenlandia, de Smith Sound, de Cumberland Sound, del Labrador, del Oeste de la Bahía de Hudson, del Río Mackenzie, de Point Barrow, de St. Michel y de las Islas Kodiak. Además, en el Área Mackenzie, entre los koyukon, los kaska y los tsetsaut; en el Área del Plateau, entre los lillooet y los thompson; en el Área del Norte del Pacífico, entre los songish, los tahltan y los tlingit; en el Área de California, entre los atsugewi, los mono del Oeste, los shasta y los yana; en el Área de las Planicies, entre los arapaho, los assiniboin, los gros ventre y los wichita; en el Área Sureste, entre los caddo, y en el Área Suroeste, entre los zuñi. Complementando esta distribución geográfica, Bierhorst (1985: 59) ${ }^{7}$ anota la existencia de este esquema en otros tres pueblos del Área Esquimal, a saber: entre los esquimales de Netsilik, los esquimales de Buffin y los esquimales Caribou.

En síntesis, puede afirmarse que el motivo A $751.5++$, que atribuye las manchas de la luna a rasguños o pintura, se asocia mayoritariamente, con las variantes anotadas, con el motivo H 58 Relato de las marcas de la mano, tanto en América del Norte como en Sudamérica (véase el Mapa 1), siendo notoria su ausencia en el Área Mesoamericana.

\section{Una rana en la luna (A 751.3)}

La explicación del origen de las manchas de la luna asociada con este motivo implica, como especificativo, el motivo A 751.3.1 ++. Lo que se ve en la luna es una rana que ha saltado a la cara de una persona y permanece allí.

Este motivo, del que solo hemos registrado versiones en pueblos de América del Norte, se manifiesta en dos esquemas narrativos, claramente diferenciados.

El primero de estos esquemas, del cual la mayor parte de las versiones mencionan tres ranas, puede ejemplificarse en un relato lillooet -pueblo Salish del Área del Plateau- recogido por James Teit y reproducido por Stith Thompson (1929/1967: 45-46), cuya traducción citamos a continuación:

Las tres hermanas Ranas tenían su casa en una ciénaga y allí vivían juntas. No muy lejos vivían muchos otros en otra casa, entre los que estaban Serpiente y Castor, que eran amigos. Estos habitaban en tierras bien cultivadas y querían casarse con las ranas.

Una noche, Serpiente llegó a casa de las Ranas y arrastrándose hasta una de ellas, le puso la mano en la cara. Ella despertó y le preguntó quién era. Al enterarse de que era Serpiente, le dijo que no se casaría con él y que se fuera enseguida. Además, lo calificó con duros nombres como "individuo fangoso", "ojos pequeños", etc. Serpiente regresó y le contó a su amigo su fracaso. A la noche siguiente, Castor lo intentó, y arrastrándose hasta una de las hermanas, puso su mano en la cara de la muchacha. Ella despertó, y adivinando quien era, le dijo que se marchara. Lo llamó "piernas cortas", "barriga grande" y "gran trasero". Castor se sintió herido y al llegar a su casa, comenzó a llorar. Su padre le preguntó qué le ocurría y el muchacho se lo 


\section{Mapa 1}

A 751.5++ Las manchas de la luna Esq.

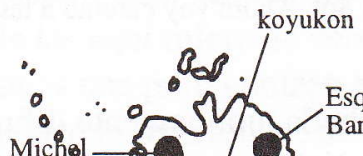

koyukon

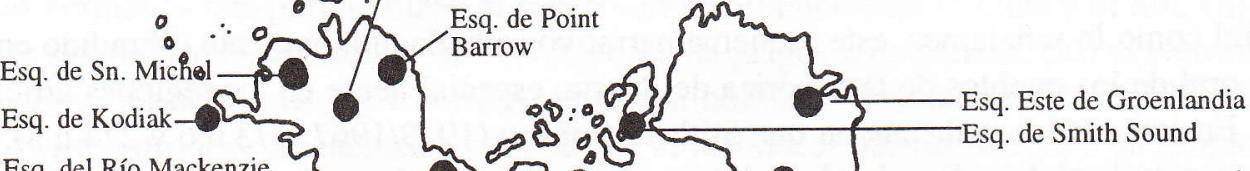

Esq. del Río Mackenzie ? 2 Esq. del Oeste de Groenlandia

Esq. Centra

\section{Rasguños}

H 58 Relato de las marcas de la mano; $\mathrm{T} 415$ Incesto de hermanohermana (Luna y Sol)

D H 58 Relato de las marcas de la mano; T 415 Incesto de hermanohermana (Luna y su hermana)

- H 58 Relato de las marcas de la mano. Luna y una mujer (u hombre) pariente del Sol

Otras versiones 
contó. Su padre le dijo: "Eso no es nada", "No llores; ¡Lloverá mucho!", pero el muchacho le contestó: "Quiero llorar". Como siguió llorando, llovió mucho y pronto se inundó la ciénaga en que vivían las Ranas, hasta quedar la casa bajo el agua. Las Ranas sintieron frío y se fueron a la casa de Castor. Allí le dijeron al padre: "Queremos casarnos con tus hijos", pero el Viejo Castor les respondió: “iNo, ustedes lo trataron muy mal!”. Como el agua era ya un río, las Ranas nadaron corriente abajo hasta llegar a un remolino que las absorbió y las hizo descender hasta la casa de Luna. Ésta las invitó a calentarse junto al fuego, pero ellas dijeron: "No, no queremos sentarnos cerca del fuego; queremos sentarnos allî”, y apuntaron hacia Luna. Ésta preguntó: “¿Aquî?”, al mismo tiempo que señalaba sus pies. Las Ranas dijeron: "No, no, alli". Luna fue señalando varias partes de su cuerpo hasta llegar al rostro. Entonces, él preguntó: “¿Quieren sentarse aquí?”, y las tres gritaron "Sí", y saltaron a su cara estropeando su belleza. Las hermanas Ranas aún pueden verse hoy en la cara de la Luna.

Según Stith Thompson (Id.: 291 n. 69), el contenido de este relato lillooet se registra en otros seis pueblos del Área del Plateau, cuales son los salish, los thompson, los coeur d'Alène, los kalispel, los nez percé y los shuswap. También, según este autor, se encuentra entre los snuqualmi, los tahltan y los coos, en el Área del Norte del Pacífico; entre los paviosto ${ }^{8}$, en el Área de California; entre los arapaho, los crow, los gros ventre, los paiute y los shoshoni, en el Área de las Planicies; entre los micmac y los montagnais, en el Área del Bosque del Noreste; entre los seneca, del Área Iroquesa, y entre los apache jicarilla, en el Área del Suroeste.

Una variante bastante alejada de este esquema -dado que en ella es un sapo el que salta a la cara de la luna- se encuentra en una versión coeur d'Alène recogida por Teit y que reproduce Lévi-Strauss (1968/1979: 80), cuyo texto citamos a continuación:

"Otrora el héroe Luna convidó a sus vecinos a una gran fiesta. Llegó el sapo cuando la cabaña
estaba ya llena. Rogó en vano que le hicieran un lugarcito, pero lo echaron fuera. Para vengar-
se, el sapo suscitó una gran lluvia que inundó la morada de Luna. Expulsados en plena noche,
los invitados vislumbraron una luz. Venía de la cabaña del sapo, donde quisieron refugiarse, ya
que sólo allí seguía seco el suelo. Entonces el sapo saltó a la cara de Luna y nadie pudo des-
prenderlo. Todavía se ve allî".

El segundo esquema narrativo correspondiente a este motivo se halla inserto como espisodio final en versiones del Mito de las esposas de los astros.

Los textos -invariablemente extensos- que cita Lévi-Strauss (1968/1979) en su análisis de este mito, ofrecen desarrollos bastante similares: los hermanos Luna y Sol desean casarse. Luna quiere hacerlo con una humana y Sol con una criatura acuática. Después de bajar ambos a la tierra, Luna llega al cielo acompañado de una muchacha indígena, en tanto que su hermano lo hace en compañía de una sapa. En este punto, optamos por citar a continuación el cierre de la versión mandan (Lévi-Strauss Id.: 266) que ilustra el esquema narrativo en cuestión:

"La madre hizo entrar a las dos mujeres, pero no le fue fácil dar con la sapa, agazapada en la maleza y que orinaba a cada brinco. Cuando se les sirvió la comida, la chica mandan escogió un pedazo de tripa delgado, la sapa uno grueso. La vieja quería averiguar quien era la mejor comedora y que haría más ruido al comer. La india tenía dientes cortantes y devoraba como un lobo. Pero la sapa no consiguió hacer chascar carbón entre sus encías. Todo el mundo se mofó de ella. Furiosa, saltó al pecho de Luna y allí se adhirió. Él la desprendió a cuchillo y la tiró al fuego. Entonces ella se le pasó a la espalda, entre los omóplatos, donde no podía alcanzarla. Tal es el origen de las manchas de la luna" 9 . 
Al margen de esta versión mandan, Lévi-Strauss cita otras cuatro versiones todas procedentes de pueblos relativamente vecinos del Área de las Planicies, cuales son los arapaho (Id.: 174-175), los gros ventre (Id.: 239-240), los crow (Id.: 240-214) y los hidatsa (Id.: 242), debiéndose señalar en lo que respecta a los tres primeros, que se trata de pueblos en los que se registran los dos esquemas aquí mencionados (véase Mapa 2).

\section{Mapa 2}

A 751.3 Una rana en la luna

Historia de Castor y las hermanas Ranas

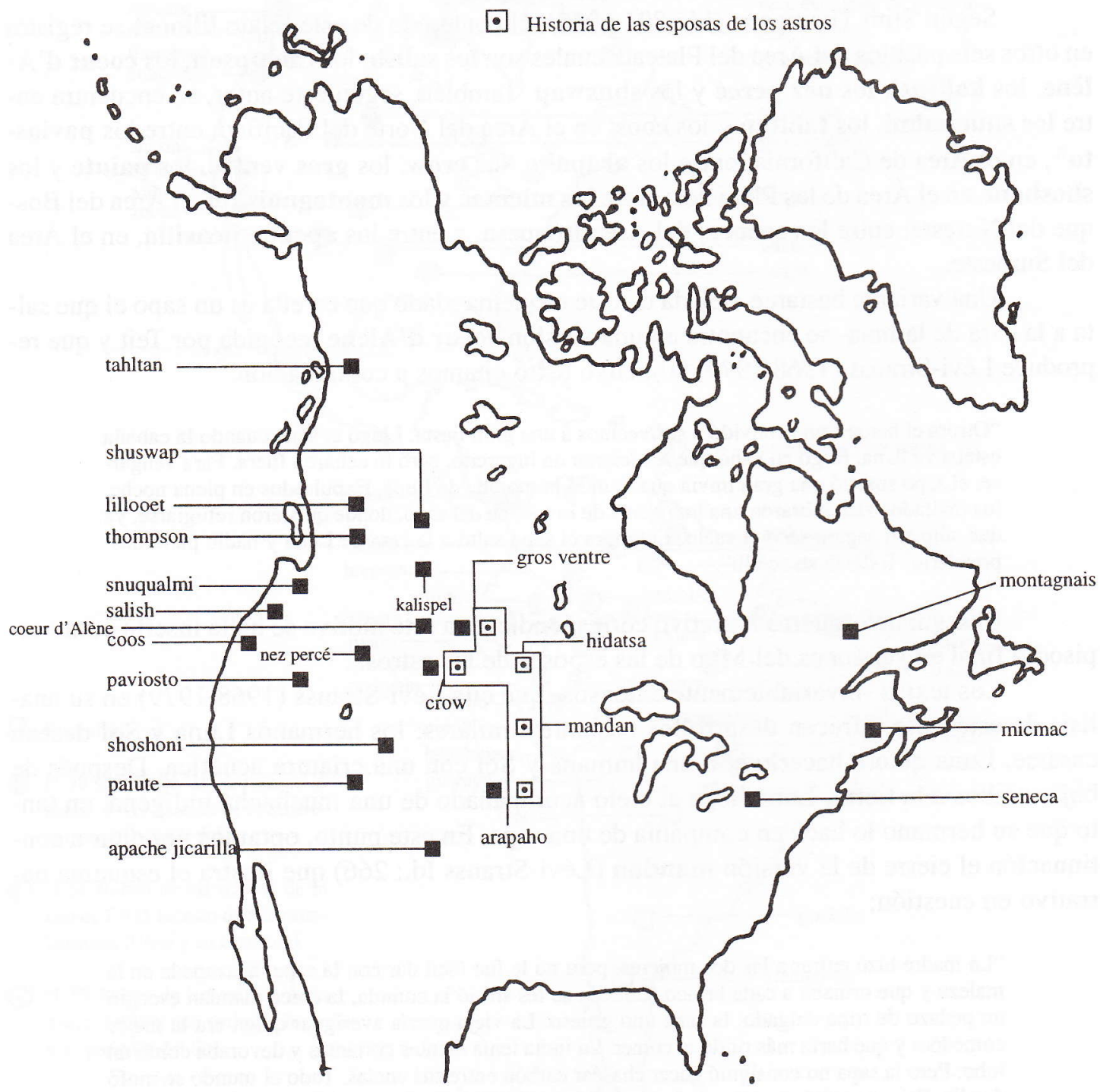




\section{Lo que se ve en la luna es un conejo (una liebre u otro animal) (A 751.2++)}

Como es obvio, las versiones correspondientes a este motivo se dividen según la especie animal cuya figura se asocia con las manchas de la luna. En lo que concierne a este trabajo, la especie reiterada la constituye el conejo, en tanto que sólo en un texto aparece en tal función "el jaguar de cuatro ojos".

\subsection{El conejo en la luna}

Conviene previamente hacer notar que todas las versiones correspondientes a este componente del motivo proceden del Área Mesoamericana.

En este sentido, la versión, al parecer, más conocida, procede de la tradición nahua y concierne al Mito de Tecuciztécatl. Según este mito, y de acuerdo con la relación de Sahagún que reproduce Krickeberg (1928/1985: 28-30), al llamado de los dioses para saber quien alumbraría al mundo, respondió ofreciéndose para ello, Tecuciztécatl ("cuatro pedernal"). Junto a él, los dioses persuadieron a Nanahuatzin ("el dios buboso") para que también se inmolara en la hoguera. Sin embargo, al llegar el momento de lanzarse al fuego, Tecuciztécatl sintió miedo y vaciló, en tanto que Nanahuatzin se arrojó sin pensarlo a las llamas. Tras él, finalmente, se lanzó Tecuciztécatl, pero cayó en las cenizas, por lo cual no tuvo suficiente brillo. Luego de que ambos se hubieron consumido en el fuego, los otros dioses se sentaron a esperar de qué parte saldría Nanahuatzin. Finalmente, por el este, salió el sol, resplandeciente y encegueciendo con sus fuertes rayos a quienes lo miraban. Después salió la luna derramando una luz tan fuerte como la del sol.

En este punto, citamos a continuación, el cierre del relato, tal como lo refiere Krickeberg (Id.: 30):

\footnotetext{
"Cuando vieron los dioses que resplandecían igualmente, se hablaron otra vez y dijeron: "¡Oh dioses! ¿Cómo será esto? ¿será bien que vayan ambos a la par? ¿será bien que igualmente alumbren?". Entonces los dioses dieron sentencia, y dijeron: "Sea de esta manera, hágase de esta manera". Y luego uno de ellos fue corriendo y dio con un conejo en la cara de Tecuciztécatl, y le oscureció la cara y le ofuscó el resplandor, y su cara quedó como está ahora".
}

A su vez, según refiere otro mito nahua (Krickeberg Id.: 31 y González Torres 1991: 106-107), cuando el sol se puso en movimiento y tras él la luna, "...ella fue recibida en la orilla del cielo por Papaztac [uno de los cuatrocientos conejos o dioses del pulque], quien le rompió "una taza con figura de conejo en la cara".

La existencia de estos mitos, considerando aún la versión referida por Alexander (1920/1964: 57), según la cual “... en los mitos mexicanos, la luna alumbraba tan brillantemente como el sol, hasta que este último oscureció a su rival lanzándole a la cara un conejo", determina que en la tradición nahua la imagen de la luna se asocie con la figura del conejo, tal como se aprecia en la ilustración del Códice Borgia que representa al Sol, la Luna, Venus y la Tierra y que aquí reproducimos, tomándola de González Torres (Id.: 157). 


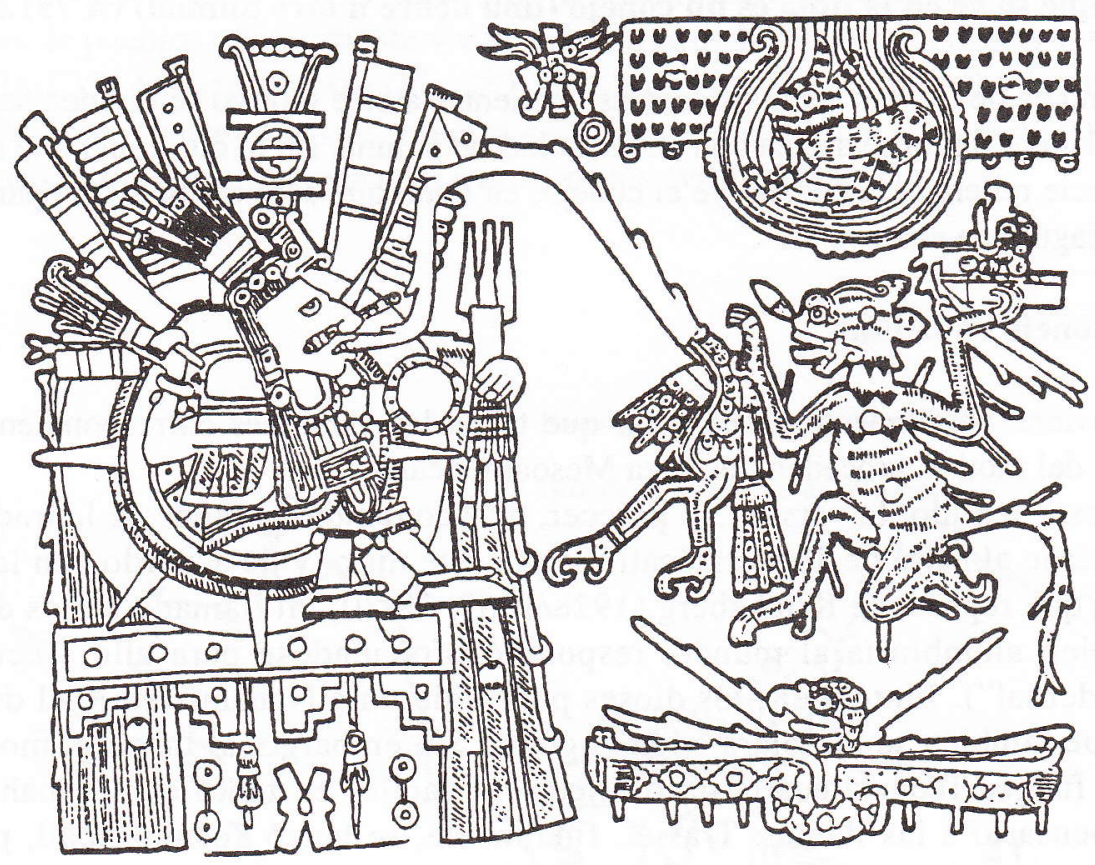

También, aunque en un esquema diferente, en la tradición oral trique, las manchas de la luna se asocian con la figura de un conejo, según se desprende de la siguiente versión publicada por Monzón (1945-1948: 7), de la cual citamos a continuación los pasajes pertinentes:

"Nexkiriac [el que hizo el mundo] deseaba que sus hijos vieran a su hermano Shische [la tierra]... Llamó a Cuhuí [el sol] y a Yahuí [la luna]. Les señaló un punto en el espacio, diciéndoles que corrieran y juntos alumbraran a su hermano Shischec. Los dos partieron con gran velocidad. Pero Yahuí, en su camino por el cielo, vio que atravesaba un conejo y se detuvo para cogerlo; en tanto que Cuhuí Nñahac se le había adelantado. Yahuí cogió el conejo y emprendió la carrera en el espacio para alcanzar a su hermano; pero al mismo tiempo que corría quería comer; y el conejo, queriendo escapar, se le atoró en la boca. Cuhuí... llegando al punto, salió grande y brillante con su color rojizo e iluminó a Shischec. Mucho después salió Yahuíc de color amarillento con su conejo en la boca".

Al margen de las versiones hasta aquí señaladas, hemos registrado en el Área Mesoamericana otras dos versiones, una tzeltal y otra chatina, que ofrecen distintas explicaciones de cómo la figura del conejo llegó a la luna. No obstante, se trata en ambos casos de episodios yuxtapuestos y fragmentarios que se encuentran insertos en textos referentes a otros contenidos míticos.

De esta manera, la versión tzeltal, referida por Eric Thompson (1970/1987: 433-434), -y que según este autor es casi idéntica a una existente en chol palencano-, tiene como protagonistas a Yax Kahkal "El sol verde o primero" y a su hermano menor, que viven con su abuela [la luna]. En cierta ocasión -refiere la versión tzeltal- el hermano menor transformó un puñado de simiente de algodón en una colmena, y persuadió al mayor para que trepara a lo alto de un árbol y cogiera la miel que había en ella. El otro así lo hizo y se comió ávidamente la miel, arrojándole al menor sólo trozos de cera. Este transformó los pedazos de cera en roedores que royeron las 
raíces del árbol haciéndolo caer. El hermano mayor se mató al estrellarse, convirtiéndose sus despojos y su sangre en animales. La versión se cierra con el episodio que a continuación citamos:

\begin{abstract}
"La abuela acusó al hermano menor de haber matado a su hermano, al ver que éste no llegaba, pero el otro lo negó. Le dijo que preparara grano para alimentar a los animales que acudirían a la choza, y que agarrara los que quisiera para tenerlos en la choza como animales domésticos. Fueron animales y aves que comen maíz los que acudieron, y ella los asió por la cola. El muchacho le dijo que si se reía de ellos se le escaparían y le dejarían la cola en las manos. Pero ella no pudo remediarlo: se rio y los animales se le escaparon dejándole la cola en las manos. Por eso el venado, el conejo y el pecarí no tienen colas verdaderas. El único que volvió a agarrar fue el conejo. Y nuestra madre celeste [la luna] todavía lo tiene, y todavía puede verse en el centro de la luna".
\end{abstract}

En lo que respecta al texto chatino, éste corresponde a un relato recogido en Oaxaca por Miguel A. Bartolomé y reproducido por Bierhorst (1990: 102-110). Se trata de un extenso texto que narra la historia de cómo los pequeños hermanos Sol y Luna, huyendo del Terror Nocturno, fueron salvados por una anciana que los libró de su perseguidor ocultándolos en su boca y que luego los llevó a su casa criándolos como a sus hijos. Según el relato, la anciana les hizo creer a los pequeños que su padre era su marido y que él vivía en el bosque, negándose a que lo vieran por el temor que ella sentía de que ellos lo mataran. Cierta vez que los hermanos la siguieron al bosque, descubrieron que el marido de la anciana, y aquel que ella les decía que era su padre, era, en realidad, un venado.

En este punto del relato se introduce el episodio pertinente al origen de las manchas de la luna y el cual, traducido de Bierhorst, procedemos a continuación a citar:

\begin{abstract}
Al día siguiente, la anciana les pidió que fueran a cortar hierbas para su marido, diciéndoles que eso era sólo lo que él comía. Los hermanos salieron e hicieron un machete de madera para cortar la hierba. Ellos cortaban la hierba con tanta energía que golpearon a un conejo y éste saltó a la cara de Luna. Lo golpeó tan fuerte que la cara de Luna quedó con la estampa del conejo. Es por eso que hasta hoy la sagrada Luna tiene la figura del conejo en la cara.
\end{abstract}

El relato continúa refiriendo cómo Sol y Luna matan al venado, rellenando después su piel con avispas, y llevándole luego la carne a la anciana. Esta la cocina y se la sirve, pero, recelosa por el canto de la rana que le dice que se está comiendo la carne de su marido, parte al bosque y golpea con una estaca la piel del venado. Lacerada por el ataque de las avispas, regresa a la casa, donde los hermanos le preparan un baño y en él terminan calcinándola. Tras esto, ambos se dirigen al cielo.

Como se desprende de lo aquí anotado, la figura del conejo en la luna presenta una distribución limitada al Área Mesoamericana, región en la cual, inclusive, tal interpretación de las manchas de la luna es, con raras excepciones (véase infra 8.5), exclusiva. En este sentido, tanto Bierhorst (1990: 103) como Eric Thompson (Id.: 443) confirman que la figura del conejo en la luna, aunque sin especificar las versiones, se encuentra entre los mixtecos, chinantecos, zapotecos y mixes, pueblos a los que Bierhorst suma los mazatecos, cuicatecos y popolucas, en tanto que Eric Thompson añade a los chiapanecos, mopanes y quichés de Chichicastenango (véase Mapa 3). 
Mapa 3

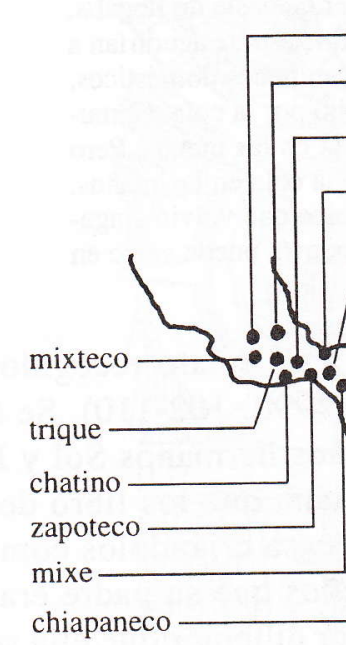
A 751.2++ Lo que se ve en la luna es un conejo (una liebre u otro animal)

- El conejo en la luna

+ Otro animal en la luna:

el jaguar-de-cuatro-ojos 
No obstante, en lo que a las versiones aquí mostradas se refiere, la perceptible diferencia que en lo que respecta al mito del origen de las manchas de la luna muestran las versiones nahuas y trique en relación con la tzeltal y la chatima, conduce a suponer que en su trayecto hacia el sur, y desprovisto el mito de su contexto teogónico, la figura del conejo llegara, con el paso del tiempo a insertarse como mero fragmento en los mitos lunares de pueblos geográficamente distantes. La pérdida del mito original y la supervivencia en él sólo de la figura del conejo, parece corroborarse en la explicación que sobre la asociación del conejo con la luna en la cultura pipil da Schultze Jena (1935/1977: 67) cuando al respecto anota:

\begin{abstract}
"De los animales... uno se identifica con la imagen de la luna por su modo de ser: Este es el conejo. En su manera de actuar, en su alegre proceder al engaño es cuando se valorizan los diversos caracteres que sobre este animal se han escrito. Al igual que las fases de la luna apareciendo unas noches al oriente y otras al occidente, así el conejo aparece en ambas entradas de su morada subterránea, manera como se establece esta conexión".
\end{abstract}

\title{
3.2. Otro animal en la luna: el jaguar-de-cuatro-ojos
}

En nuestro conocimiento, obra sólo una versión en la que un animal distinto de conejo se asocia con el mito del origen de las manchas de la luna. Se trata de una versión yuracare -pueblo del Área Amazónica situado al este de Bolivia- recogida por Alcide D’Orbigny en la primera mitad del siglo diecinueve, y referida por Métraux (1948c: 502-503). En ella, la figura del animal en la luna es la del "jaguar-de-cuatro-ojos".

Como en textos precedentes, el motivo se da en un episodio fragmentario que en este caso se inserta en la Historia de Tiri. En la versión referida por Métraux, una mujer, tras abandonar su casa y perderse en la selva, llega a la casa de los jaguares. La madre de ellos la oculta hasta que uno de los animales, el jaguar-de-cuatro-ojos, la descubre, la mata y saca a Tiri, el niño que la mujer llevaba en el vientre. Tiri crece con la anciana y con los jaguares hasta que en cierta ocasión, la paca le revela su origen y la manera cómo fue muerta su madre. El muchacho regresa a la casa y mata a flechazos a tres jaguares. Nuestra traducción de la versión de Métraux en lo que respecta al episodio que sigue a este hecho, es la siguiente:

El jaguar-de-cuatro-ojos vio el peligro, y trepando a lo más alto de un árbol gritó: “¡Árboles, palmas, ayúdenme! ¡Estrella, ayúdame! ¡Luna, ayúdame!” La luna lo cogió y lo mantuvo con ella. El jaguar-de-cuatro-ojos puede verse hasta hoy en la luna.

\section{Hombre en la luna (A 751)}

Este motivo, poco frecuente en la tradición oral indoamericana, lo hemos registrado en tres textos de muy distintos contenidos. Se trata de textos guajiro, chorote y toba, el primero correspondiente al Área Caribeña, y los dos últimos al Área del Chaco.

En lo que respecta al texto guajiro, el motivo del Hombre en la luna se encuentra en una mera alusión contenida en un pasaje de la extensa Historia de los hermanos Peeliyuu y Tumájü'le (Wilbert y Simoneau 1986: 54-63).

No obstante que en ella la manifestación del motivo presenta esta característica, sintetizaremos el contenido de toda la Historia ya que ésta presenta en su desarrollo elementos 
que se encuentran en versiones ya aquí consideradas y cuyo cotejo revela aspectos de interés. La síntesis es la siguiente:

Embarazada por el Fuerte Invierno, Manna decide huir donde su abuela. Durante siete meses deambula por la selva conversando con los milagrosos "retoños de su vientre". Extraviada, Manna llega a la casa de Kalamantuunay, madre de los jaguares, mitad fieras y mitad humanos. Al aproximarse sus hijos, la mujer oculta a Manna, pero cuando ellos dicen sentir olor a carne, les revela dónde está la muchacha. Los jaguares-hombres destrozan y devoran a Manna, pero mezclados con las partículas de su carne, caen en la hierba cinco minúsculos niños, de los cuales tres mueren ahogados por la orina de los jaguares-hombres. Rescatados los dos restantes, Peeliyuu y Tumájü'le, ellos crecen al cuidado de Kalamantuunay, quien los cría y alimenta pensando en comérselos algún día. Los dos muchachos se convierten en diestros cazadores, más certeros que los jaguares-hombres. En cierta ocasión, uno de éstos propone realizar una prueba: ... "La prueba propuesta por la fiera no era fácil. La flecha tenía que ser disparada hacia la luna y tenía que golpear las pupilas del hombre que desde allí miraba". Los jaguares-hombres resultan vencidos y los muchachos siguen cazando. En sendas ocasiones, primero la paloma silvestre y luego el guacamayo, les revelan que ellos no son hijos de los jaguares. Los dos hermanos llegan a la casa con un venado muerto y le piden a Kalamantuunay que lo cocine. Cuando ella lo está haciendo, la empujan dentro del caldero. Luego la decapitan, ponen su cabeza dentro del caldero, y mezclada con la del venado sirven su carne a los jaguares-hombres. Tan pronto como éstos comienzan a comer, sus molares, sus labios, sus dientes y hasta las cucharas, los tazones y el caldero empiezan a decirles que se están comiendo a su madre. Llevados por la curiosidad, ellos revuelven el caldero y encuentran la cabeza de la mujer. Entonces salen en persecusión de los dos muchachos, pero éstos huyen convertidos en nube. Los jaguares-hombres se transforman en viento y tratan de disolver la nube, pero fallan y se quedan flotando en el aire como espíritus malignos.

Este relato guajiro contiene elementos tan similares al relato yuracare (véase 3.2) que cabe suponer que ambos desarrollan el mismo esquema narrativo: la mujer preñada que, perdida en su viaje, llega a la casa de los jaguares; la falsa acogida de la madre de estos a la recién llegada; su muerte, devorada por los felinos y la supervivencia del o de los hijos que lleva en el vientre; la crianza de éstos por la madre de los jaguares; la revelación que ciertos animales le hacen a los hijos sobre su verdadero origen, y el castigo de los jaguares, constituyen componentes narrativos que concurren paralelamente en ambos textos. Por otra parte, el relato guajiro contiene un elemento que lo asocia con el texto chatino (véase 3.1), cual es el episodio en el que un animal, o bien partes del cuerpo u objetos culinarios le advierten a alguien que se está comiendo la carne de un familiar.

No obstante, y al margen de lo interesante que resulta percibir la existencia de estos componentes en textos originados en zonas geográficamente tan distantes, lo que en nuestro caso estimamos de mayor relevancia es el hecho de que se trata de tres relatos en los que de manera fragmentaria y sin que ofrezca una relación específica con sus respectivos desarrollos, se inserta en ellos el mito del origen de las manchas de la luna.

Tal como se señaló, las otras dos versiones en las que se manifiesta este motivo corresponden respectivamente a un texto toba y a otro chorote. En el caso del texto toba, se 
trata del relato "La caza del avestruz", recogido por Lehmann-Nitsche (1923: 281-284), y cuyo desarrollo contiene numerosas referencias etnoastronómicas entre las cuales el origen de las manchas de la luna no se explicita en el texto mismo, sino que se incorpora en una nota como interpretación del informante. La síntesis de los acontecimientos que conducen a la situación en que se manifiesta el motivo, es la siguiente:

Tres hombres, acompañados de sus perros, intentaban cazar una avestruz. Ésta subió al cielo seguida por los tres perros y por uno de los cazadores. Al verse solo en el cielo, el cazador envió a un águila en busca de sus dos compañeros. Ya ellos allí, el cazador mandó a uno a cuidar "la casa de las tres viejas" 10 y al otro lo envió hacia la salida del sol para que no se le escapase el avestruz, diciéndole que luego iría a encontrarse con él. El hombre partió y estuvo allí largo rato. Cansado de esperar, decidió regresarse y llegó así a una casa-quinta cuyo dueño le proporcionó un caballo para que fuera a buscar a su compañero. Al no encontrarlo, el hombre comenzó a llorar. Vino entonces Dios y le preguntó por qué lloraba.

A partir de este punto, citaremos textualmente el relato, incorporando en el paréntesis cuadrado la nota de Lehmann-Nitsche (Id.: 282 n.4) referente al motivo de nuestro interés:

“...el hombre le contestó: "Lloro porque estoy triste, porque he perdido a mi compañero y es-
toy solo; a ver si me das un trabajo para trabajar aquî". Dios le dijo: "Bueno", y le dio un tra-
bajo, y este trabajo era para toda la vida. Desde entonces el hombre es nuestra luna. Para tra-
bajar, Dios le dio un caballo blanco, alto y gordo. Con él, Luna [las manchas lunares represen-
tan, según el indígena, un muchacho jinete con un hacha sobre el hombro] ... bajó a la entrada
del sol, tomó el camino subterráneo, salió allá a la salida del sol y volvió a la casa de Dios..."

En cuanto al texto chorote, se trata de un relato recogido por Celia Mashnshnek y reproducido en inglés por Wilbert y Simoneau (1985: 100). Nuestra traducción de este texto es el siguiente:

Luna es un hombre que vivía en la tierra. Reunió a todas las tribus: los mataco, los toba, los chulupí, los tapieté y los chiriguano. Él les enseñó a los toba a construir su aldea. Luego construyó otras casas en la aldea de los mataco, y así siguió hasta llegar a la Merced, donde nosotros vivimos ahora. Luego, él se fue a La Gracia. Luna construyó las casas del pueblo y les dijo: "Ahora yo me volveré al cielo". Él subió. Nosotros siempre vemos a un hombre que aparece directamente en la mitad de la luna. Él es la luna misma. La luna se extiende como un largo espejo y este hombre se encuentra en la mitad. Se ve como si estuviera rezando, con las manos elevadas.

\section{Mujer en la luna (A 751.8)}

Tan poco frecuentes como el Hombre en la luna son, al parecer, las manifestaciones del motivo A 751.8 Mujer en la luna, del cual hemos registrado tres versiones: dos en América del Norte -una chippewa, correspondiente al Área del Bosque Central (WDL. CENT.), y otra blackfoot, correspondiente al Ârea de las Planicies (PLNS.)- y una en América del Sur, procedente esta última de la tradición quechua huanca, correspondiente al Área Peruana.

En el caso de la versión chippewa, se trata de un relato recogido en las riberas del Lago Superior por Ephraim Squier en la primera mitad del siglo diecinueve y publicado por Ella E. Clark (1960/1991: 123-126). En él, se narra la historia de Lone Bird ('Ave Solitaria'), la hermosa hija del jefe Dawn of Day ('Albor del Día'). 
Con un estilo no exento de lirismo, la narración refiere cómo Ave Solitaria acogía con frialdad a todos los jóvenes que la pretendían, manifestando que vivía feliz junto a sus padres. Angustiado por esta situación, Albor del Día organizó una carrera anunciando que el ganador obtendría a su hija. Sin embargo, repetida una y otra vez la prueba, siempre llegaban empatados los dos pretendientes más renombrados. Cuando tras esto, y para dirimir el empate, se organizó una competencia de caza en la que ambos jóvenes cazaron exactamente el mismo número de piezas, Albor del Día interpretó este resultado como la voluntad del Gran Espíritu y desistió de sus propósitos. Después de esto, y a medida que pasaba el tiempo, Ave Solitaria, entristecida por su soledad, se abandonaba a lúgubres pensamientos en las riberas del lago.

A continuación, citamos nuestra traducción de los pasajes finales del relato chippewa:

\begin{abstract}
Por largo rato, la muchacha estuvo en la roca junto al lago, sumida en tristes pensamientos. Cuando se levantó para irse, ya caía la noche y la luna llena hacía un camino de plata sobre las aguas. Ave Solitaria miró largamente la brillante esfera en el cielo. Extendiendo hacia ella los brazos, exclamó en voz alta: "“Oh, cuán hermosa eres. Si yo hubiera tenido alguien como tú a quien amar, hubiera sido amada por ti y ya no estaría tan sola!”. El Gran Espíritu escuchó su voz y rápidamente la condujo hasta la luna. Mientras tanto, su padre ya había terminado su trabajo. Al no verla, regresó al lugar donde había hecho el azúcar de meple. Allí la estuvo llamando, pero nadie le respondió. Triste y ansioso, alzó sus ojos hacia el cielo, hacia la luna que brillaba intensamente. Allí vio a su hija en los brazos de la luna. Reconfortado por esta imagen, dejó de preocuparse. Supo que su hija siempre estaría cuidada con ternura... La cara de Ave Solitaria aún se ve en la luna, y ella aún mira hacia abajo, hacia su pueblo que todavía cuenta su historia a la luz de las fogatas".
\end{abstract}

En lo que respecta a la versión blackfoot, recopilada por C. Wissler y D.C. Duvall, citamos a continuación, sin comentarios, la referencia que de ella hace Lévi-Strauss (1971/1987: 205):

“...una mujer adúltera, que dejó a los suyos para irse a vivir con un personaje lunar, se disfraza de hombre a fin de volver a ver a sus hijos. Estos son los primeros en reconocerla, y luego su padre, que quiere matar a la infiel; pero ella escapa por el agujero del humo, parecida a un meteoro, y el hombre no consigue más que cortarle la pierna con un cuchillo. La mujer vuelve a la luna y a su amante. Sigue viéndose sobre el astro su forma mutilada".

Finalmente, la versión quechua huanca se encuentra en el relato "La hilandera de la luna", recogido y publicado por Villanes Cairo (1992: 94-104).

La narración, cuyo acentuado lirismo acusa una reelaboración de su recopilador, refiere la historia de una misteriosa mujer que como prisionera del jefe Loparin, llegó al valle de los huancas y que al morir éste destrozado por un cóndor, siguió viviendo en el palacio que Loparin había hecho construir para ella. Confinada en aquel lugar -prosigue el relato- la extraña mujer hilaba día y noche vellones de los más sorprendentes colores, despertando con ello la curiosidad y la envidia de las mujeres del lugar. Cierta vez que las mujeres llegaron al palacio para verla hilar, ella le dijo a una de las jóvenes que regresara cuando hubiera luna llena y que entonces le enseñaría cómo hacía sus tejidos. Acudió la joven y vio cómo la mujer, yéndose a la cima de un cerro, invocaba a los elementos, haciendo que el viento hiciera descender una nube que transformada en finísima lana se enredó en sus brazos y que tras esto apareciera el arcoiris que le dio a la lana los más bellos colores. Cuando días después, la joven volvió al palacio de la hilandera, ésta le dijo que ese mismo día partiría para unirse al arcoirirs. Acompañada por la muchacha, la mujer subió a la cima del cerro, pero entonces el 
viento, celoso por la unión de la mujer con el arcoiris, formó una tolvanera que elevó a la hilandera por los aires hasta depositarla en la luna. El relato termina refiriendo: "Desde entonces la figura de la hilandera, con su penacho y las dos grandes plumas de cóndor sobre la cabeza, está sentada en la luna, huso en mano, mezclando matices para los tejedores".

Como resulta evidente, tanto el motivo A 751 Hombre en la luna, como el motivo A 751.8 Mujer en la luna, presentan en Indoamérica una escasa frecuencia de versiones cuyos contenidos, por otra parte, son notoriamente distintos.

\title{
6. Imágenes misceláneas en la luna (A 751.9)
}

La única versión correspondiente a este motivo de la que tenemos conocimiento, se encuentra en un texto caduveo, pueblo de filiación guaycurú asentado al sur de Mato Grosso, cerca de la frontera con Paraguay. Se trata de un breve relato recogido por Vojtéch Frič y editado por Wilbert y Simoneau (1989: 49), cuya traducción ofrecemos a continuación:

\begin{abstract}
Una vez los caduveo robaron un caballo. Como no sabían para qué servía, no estuvieron contentos con él. "¿Para qué será bueno este monstruo?". El ibis oyó el comentario y se lo mencionó a Ninigo, quien cogió algunos frutos de genipapo e hizo con ellos una pintura. En la luna pintó un hombre a caballo, pero la pintura no tenía mucha semejanza. Sin embargo, los caduveo la vieron y la entendieron. Hicieron una montura y montaron el caballo que habían robado. Desde entonces ellos tienen muchos caballos.
\end{abstract}

\section{Otras marcas en la luna (A 751.11)}

Agrupadas bajo este motivo se disponen variadas versiones en relación con el mito que es objeto de este trabajo. Cabe aquí señalar que entre estas versiones ofrecen una mayor frecuencia las que asocian las manchas de la luna con quemaduras. A continuación, expondremos estas versiones según la explicación que ellas manifiestan en sus respectivos contenidos.

\subsection{Las manchas de la luna son quemaduras}

Entre las versiones que atribuyen las manchas de la luna a quemaduras, cabe distinguir un conjunto de relatos, todos ellos procedentes de pueblos gê de las áreas Amazónica (AM.) y del Este del Brasil (E.BR.), que enmarcan esta situación en la difundida Historia de Sol y Luna.

En esta extensa historia -en la que concurren los motivos A 736.6 Sol y Luna como amigos y A 736.3.2 Sol inteligente y Luna estúpido -los dos amigos, Sol y Luna (respectivamente, Pud y Pudleré, para los krahó; Pud y Pudlêra, para los apanyekra; Put y Puduvrí, para los ramkokamekra; Mabapame y Bruburé, para los apinayé o Waptokwa y Wáirie, para los sherente) deambulan por la tierra, de la que son los primeros habitantes, dando origen a la gente, a los utensilios de trabajo, a la vida breve, etc., al mismo tiempo que, siempre por la torpeza de Luna, se originan los cataclismos como la Gran Inundación y el Gran Incendio del Mundo.

Precisamente, en el marco de esta Historia tiene lugar el episodio que refiere el origen de las manchas de la luna, el cual hemos registrado en las versiones kayapó (AM.), 
recogida por Anton Lukesch (Wilbert y Simoneau 1978: 65-66) ${ }^{11}$, ramkokamekra (AM.) v.1., recogida por Curt Nimuendajú (Wilbert y Simoneau Id.: 59), v.2., recogida por W. Crocker (Wilbert y Simoneau 1984a: 24-25), apinayé (AM.), recogida por C. Estevão de Oliveira (Wilbert y Simoneau 1978: 64), crenyé (AM.), recogida por C. Nimuendajú (Wilbert y Simoneau Id.: 67), apanyekra (E.BR.), recogida por Pompeu Sobrinho (Wilbert y Simoneau Id.: 34), krahó (E.BR.), recogida por Harald Schultz (1950: 56) y sherente (E. BR:), recogida también por C. Nimuendajú (Wilbert y Simoneau 1984a: 35), si bien esta última ofrece, tal como se verá más adelante, variantes de cierta relevancia en relación con las anteriores.

En el marco de la Historia de Sol y Luna, el episodio del origen de las manchas de la luna tiene lugar cuando ambos amigos se disponen a comer la carne, específicamente el hígado, de un capybara ${ }^{12}$. A continuación, citaremos nuestra traducción de los respectivos pasajes de las versiones apanyekra (a), en la que Sol quema por casualidad la barriga de Luna con la carne del animal, crenyé (b), en la que lo hace por enojo, y ramkokamekra v.1 (c), en la que lo hace por gusto con el pretexto de despertarlo:

(a) Mientras su compañero permanecía tendido en el suelo con su estómago hacia arriba, Pud asaba el capybara. La grasa del animal se derretía en el fuego y chorreaba hasta el suelo. Pud extrajo un trozo del hígado para Pudlêra, pero cuando logró levantarlo, tropezó y cayó encima de su amigo, quien resultó con su estómago severamente quemado por la grasa chirriante del capybara. Es por eso que la luna está manchada; (b) Luna le pidió a Sol el hígado de capybara. Sol le dio un capybara entero, pero cuando lo estaba cortando, Luna se quejó de que el animal estaba muy delgado. El Sol se enojó y le gritó: "¡Justamente ahora te di un capybara entero y no estás satisfecho!". Entonces cogió del suelo un trozo de carne asada y lo lanzó a la cara de Luna. Luego agarró a Luna y lo empujó dentro del río; (c) Después de comer lo poco que le tocó, Luna, molesto, cansado y hambriento, se tendió y se quedó dormido, mientras que Sol asaba el hígado [del capybara] bajo las cenizas. Cuando estuvo asado, lo sacó, se subió sobre Luna que dormía, y se lo arrojó sobre la barriga, gritándole: “¡Despierta y come!”. El hígado caliente quemó gravemente la piel de Luna. "Corre y zambúllete en el agua", le aconsejó Sol, y Luna corrió hacia el arroyo para refrescarse.

Tal como se señaló, la versión sherente representa una variante en relación con el resto de las aquí mencionadas. En ella, aunque siempre inserta en la Historia de Sol y Luna y manteniéndose los motivos básicos, el hígado o la carne del capybara es reemplazada por huevos de avestruz, tal como se aprecia en la siguiente traducción del episodio:

Waptokwá y Wáirie habían juntado huevos de avestruz. Waptokwá los cocinó en las cenizas y abrió uno. Cuando Wáirie vio la hermosa yema, le preguntó a Waptokwá cómo había abierto el huevo. Waptokwá le mintió diciéndole que lo había golpeado contra su estómago. Entonces Wáirie cogió un huevo caliente y lo golpeó contra su estómago, de tal modo que al reventarlo, el contenido caliente le quemó la piel. Desde entonces, la luna tiene la barriga manchada.

Al margen de las aquí señaladas, hemos registrado otras versiones que, atribuyendo también a quemaduras las manchas de la luna, ofrecen distintos contenidos con respecto a los de las recién expuestas.

Una de estas versiones comparte, no obstante, con los relatos gê la caracterización de Luna como varón. Se trata de un breve relato recogido por Johannes Wilbert entre los yanomami, pueblo del extremo sur de Venezuela y correspondiente al Área Amazónica. A continuación, incorporamos la traducción de los pasajes pertinentes de la versión en inglés del texto editado por Wilbert y Simoneau (1990: 30): 


\begin{abstract}
El Sol es un hombre y también lo es Luna. Ambos se consideran enemigos por algo que voy a relatar. Un día, Luna le dijo a un hombre que fuera y juntara leña, y el hombre obedeció. Cuando llegó con la madera, Luna no estuvo satisfecho. Él quería mucha más así que envió al hombre de regreso al bosque. El hombre comprendió que lo que Luna quería era comérselo y escapó donde el Sol en busca de refugio y protección. El Sol lo ocultó. Cuando llegó Luna buscando a su presa, el Sol le dijo que no lo había visto. Enojado, Luna insistió pidiéndole al Sol buscarlo aún dentro de su casa. El Sol, entonces, le quemó la cara y es por eso que la luna tiene esas cicatrices que hoy le vemos.
\end{abstract}

Las restantes versiones coinciden en la concepción de la luna como mujer. Entre éstas, hay dos que refieren el mismo contenido mítico. Son dos versiones pertenecientes a la tradición oral selk'nam, pueblo ya extinto que habitaba la Isla Grande de Tierra del Fuego, y correspondiente, por ende, al Área Fueguina.

Ambas versiones sitúan el origen de las manchas de la luna en el mito del Na máten, 'La matanza de las mujeres', el cual no sólo es de una importancia capital dentro de la tradición cultural de este pueblo, sino que, además, constituye un episodio generador de muchos comportamientos sociales que los selk'nam conservaron hasta su extinción, ocurrida en el tercer decenio del presente siglo.

La contextualización del mito del Na máten puede sintetizarse en los términos siguientes: En el tiempo mítico, las mujeres, comandadas por la Luna, una mujer chamán enérgica y vengativa, gobernaban sin piedad a los hombres, quienes, además de ocuparse de los niños y de las tareas domésticas, vivían en un abyecto temor y sometimiento. Con el fin de perpetuar su dominio, ellas vivían en el "hain" ('la choza grande'), un lugar vedado a los hombres, donde se fabricaban y conservaban las máscaras y los trajes con que las mujeres, disfrazadas de horrorosos y malignos espíritus, llegaban al poblado para provocar en los hombres admiración y terror.

Según el mito, cierto día que el Sol, marido de la Luna, arrastraba un animal recién cazado, se aproximó al "hain" y escuchó a dos muchachas que, riéndose, comentaban lo cómico que era burlarse de los hombres haciéndoles creer que ellas eran espíritus. Comprendiendo el Sol toda la verdad, corrió al poblado y les comunicó al resto de los hombres su descubrimiento. Furiosos todos ellos, acordaron atacar el "hain" y exterminar a todas las mujeres allí reunidas.

En este punto del mito se inicia el episodio correspondiente al origen de las manchas de la luna. De él, citaremos a continuación los pasajes pertinentes de la relación hecha por Chapman (a) (1985/1988: 109-110), y luego el texto de la versión que se encuentra en Gusinde (b) (1937/1990 Tomo I, Vol. II.: 847):

(a) "En medio de la confusión las mujeres se apresuraron a apagar el fuego del hain, aunque el rescoldo siguió ardiendo. Los hombres cayeron sobre ellas con sus garrotes y atravesándolas con sus flechas. Ellos atacaron a ciegas. La masacre no se detuvo; maridos matando a sus esposas, padres a sus hijas. La bella Tamtam ['Canario'] fue ultimada por el Sol, su padre... La osadía del Sol llegó hasta el extremo de atacar a Luna, su indomable esposa, el cerebro rector. Empuñó un leño largo, agarrándolo del fuego humeante, y tres veces la golpeó... Abatida por los feroces golpes, Luna cayó de bruces sobre el fuego. Se comentó después que Viento, el hermano de Sol, la agredió también con una antorcha encendida, pero nadie se atrevió a darle el golpe mortal. Con la cara desfigurada por quemaduras, Luna huyó al firmamento perseguida por su iracundo marido. Y Sol la perseguirá por siempre sin alcanzarla jamás. Y Luna desde el lejano cielo mirará a la Tierra -su cara tiznada y surçada por las cicatrices de las heridas que sufrió durante la gran rebelión-, y jamás perdonará a sus enemigos, los hombres, y por toda la 
eternidad se esforzará por vengarse de ellos"; (b) "Los hombres furiosos tomaron por asalto desde ambos lados la Casa Grande. Inmediatamente, todos se abalanzaron sobre la mujer-luna, que era la cabecilla entre las mujeres. Todos los hombres la empujaron al mismo tiempo; la empujaron cada vez más hacia el fuego, hasta que cayó en él. Su rostro sufrió horribles quemaduras. Las cicatrices de estas quemaduras y las mancha negras en su cara se reconocen aún hoy claramente" 13 .

Finalmente, las dos últimas versiones que hemos registrado en lo que se refiere a atribuir las manchas de la luna a quemaduras y en las que, al igual que en las tres anteriores, se concibe al astro como una entidad femenina, corresponden la primera a una versión shipibo (v.2) recogida por F. Odicio, y la segunda a un breve relato cuiva recogido por Francisco Ortiz. A continuación, citaremos la referencia a la versión shipibo (a) hecha por Cárdenas Timoteo (1989: 122), y nuestra traducción del texto cuiva (b), editado en inglés por Wilbert y Simoneau (1991: 27-28):

(a) "... la luna era una deidad inmaculada que no debería tener contacto con el Sol. Pero el viejo astro se dejó arrebatar por un amor senil y persiguió a la doncella en loca carrera que lo aproximó tanto a ella hasta imprimirle un ósculo de fuego manchando para siempre su blanca faz"; (b) La Luna tiene manchas porque su marido, llamado Yupunéi, la quemó. Ella se llama Mayunéi. Yapunéi se enojó y quemó a su mujer en el estómago; también él la golpeó con una cuerda. El hombre es bien parecido. Tiene la cara roja; él se pinta con annato. Tiene una larga barba y usa un sombrero azul ${ }^{14}$.

\subsection{Las manchas de la luna son huellas de una mano (sucia) o de dedos chamus- cados}

En lo que respecta a este componente, hemos registrado tres versiones. La primera de ellas, correspondiente al Área Intermedia, es un relato waunana, en tanto que la dos restantes, procedentes del Área Amazónica, se contienen en un relato jívaro (v.2) y en un texto sirionó.

El relato waunana (Instituto Nacional de Cultura de Panamá - Instituto Lingüístico de Verano 1980: 74), pueblo chocó del extremo oeste de Panamá y del extremo Occidental de Colombia, refiere que en tiempos remotos hubo dos gemelos que, nacidos de una pantorrilla, se criaron solos. Cuando llegaron a adultos, preguntaron cómo habían muerto sus padres y la gente les respondió que habían sido devorados por los tigres. Ellos, entonces, buscaron y exterminaron a todos los tigres. Cuando volvieron a preguntar cómo habían muerto sus padres, la gente les dijo que habían sido muertos por las culebras, tras lo cual mataron también a todos estos animales. Al preguntar por tercera vez cómo habían muerto sus padres, se les dijo que la luna los había matado.

A continuación, citamos del cierre de este relato los pasajes pertinentes a este estudio:

"Uno de ellos dijo: "Con mis manos mataré a esa luna". Una vez elaborado el plan de venganza contra la luna, cortaron trozos de bambú bien largos los cuales fueron amarrados unos con otros, formando así una especie de escalera que levantaron en el aire (hacia la luna). A medida que los bambúes se elevaban, iban agregando otros a fin de hacerla lo más larga posible. Cuando ya estuvo cerca de la luna cogió otro bambú y lo añadió hasta lograr tener la luna al alcance de su mano. Entonces trató de agarrarla, pero en ese momento vino un pájaro carpintero... y dio un picotazo en mitad de la escalera partiéndola en dos. Pero él se había amarrado con fibra de la chunga, cubriéndose todo el cuerpo con ella, la que lo llevó flotando en el espacio como si tuviera alas. De esta manera fue a dar a la orilla del mar por donde cae el sol... Se dice 
que es así como aparecieron las manchas de la luna que son huellas de la mano de este personaje nacido de una pantorrilla, quien al tratar de agarrar la luna con la intención de tirarla al suelo, dejó impresa su mano en ciertas partes de ella. Esto sucedió hace mucho tiempo".

Por su parte, el relato jívaro (v.2) corresponde a un pasaje de la "Historia de Etsa, Nantu, Auju y Kujáncham”, recogida y publicada por Pellizzaro (1990/1996: 72-4).

Según refiere esta Historia -en la que concurren varios mitos de origen- Etsa (Sol) y su hermano Nantu (Luna) compartían la misma mujer: Auju. Nantu, sin embargo, comenzó a sentir crecientes celos de su hermano hasta que, impulsado por éstos, agredió a Etsa, quien tras ello partió al cielo maldiciendo la unión de una mujer con dos o más hombres [Mito del origen del tabú de la poliandria]. No obstante, al poco tiempo, Nantu se percató de que Auju era golosa y ociosa, por cuya razón decidió también subir al cielo trepando por el bejuco que para ese fin había en la Tierra. Al lugar donde Auju quedó con el hijo de Nantu, llegó Kujáncham, el zorro, quien comenzó a convivir con ella. Preocupada por tener que ocultarle a su hijo sus relaciones con Kujáncham, Auju le ordenó al zorro que trepara al cielo y trajera de regreso a Nantu para que saliera de caza con su hijo, pensando que de esta manera ella tendría ocasión de cohabitar con Kujáncham.

En este punto sigue el episodio del mito aquí estudiado y que reproducimos textualmente:

\footnotetext{
"Kujáncham, que deseaba mucho a Auju, subió al cielo y agarró a Nantu para llevarlo a la tierra. Nantu indignado contra el concubino de su mujer, en su ardor, le quemó las manos y de un empujón lo tiró a la tierra, en donde se estrelló como un bólido. Hasta ahora podemos ver en la luna esas manchas, que son los dedos chamuscados de Kujáncham, el zorro".
}

La Historia finaliza cuando, tras esto, la propia Auju sube al cielo, pero Etsa envía a la ardilla a roer el bejuco. Cuando éste se corta, Auju se precipita a la tierra convertida en lechuza y partes de su cuerpo en arcilla [Mito del origen de la arcilla].

Finalmente, en el caso de los sirionó -pueblo de estirpe tupi-guaraní del oriente de Bolivia- el origen de las manchas de la luna se encuentra en un breve pasaje del extenso Mito de Dshyási [la luna] (Califano 1976-1977: 100-127), considerado por los nativos de esta etnia como "el relato del principio".

En lo substancial, el Mito de Dshyási refiere cómo tras haber sido asesinado su hijo, Dshyási emprende una búsqueda de los culpables con acciones punitivas que van desde la transformación de una parte de la humanidad en animales, hasta la imposición a los restantes del sufrimiento y del trabajo. El referido pasaje (Califano Id.: 117) es el siguiente:

\footnotetext{
"Vinieron unos amigos de Dshyási. Querían agarrarle sus cosas para comer. Las cosas importantes de Dshyási. Vio que la mano estaba muy sucia y a Dshyási no le agradó que agarren sus

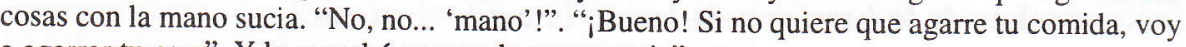
a agarrar tu cara". Y le manchó su cara la mano sucia".
}

\subsection{Las manchas de la luna son marcas de golpes}

En el ámbito indoamericano, sólo hemos registrado una versión relacionada con esta explicación del origen de las manchas de la luna. La versión, procedente del Área Caribeña, 
corresponde a un relato piaroa recogido por Boglár y editado por Velázquez (1993: 33-39). Según este relato, cuando Wajari creó el sol, éste no alumbraba nada y terminó perdido entre las montañas. Wajari, entonces, recorrió en su búsqueda los lugares sagrados.

A continuación, citamos el cierre del relato, el cual contiene la referencia al origen de las manchas de la luna:

"Al fin lo encontró y tomándolo dio un salto tan grande con él que lo colocó en el firmamento y lo puso a calentar muy fuerte. Cuando Wajari saltó con el sol, se escuchó un trueno, era la voz del báquiro. Wajari elevó más el sol y sus rayos llegaron a todas partes para que el mundo lo viera. Su hermano Buoka, que había creado la luna, quiso hacer lo mismo con ella; la tomó, saltó, pero su salto no fue tan grande como el de Wajari ya que pegó contra el firmamento y la luna se golpeó la cara, luego la colocó un poco más abajo del firmamento y no le dio calor como hizo Wajari con el sol".

\subsection{Las manchas de la luna son de sangre lanzada a su cara}

El contenido correspondiente a este enunciado se encuentra en un relato referente a la historia de la luna, originado en la tradición oral matsiguenga (Baer 1984/1994: 249-252), pueblo que habita en el oriente del Perú y que por consiguiente pertenece al Área Amazónica.

A continuación, citaremos los pasajes de este relato que guardan relación con el origen de las manchas de la luna, haciendo notar que los paréntesis que aparecen en la cita corresponden al original:

"Antes vivía un hombre con su mujer, y también sus hijos y una hija. Y no conocían (la) yuca, (sino que) comían tierra (barro). Entonces le llegó a su hija la pubertad, y le encerró su mamá. Fueron al monte, para traer tierra, y la madre dijo a su hija: "me voy a traer yuca, no salgas afuera”, y le dio tierra, para que coma. Entonces ella vio llegar a Luna. Él le dijo: "¿dónde está tu mamá?" Y ella le dijo: "ha ido a traer yuca”. Entonces él le dijo: “¿dónde hay yuca?" Ella le mostró tierra: "aquí está la yuca". Pero él le dijo: "eso es tierra", y cogió él la yuca verdadera que había traído y le dijo: "ahí está la yuca" y le dio de comer. Luego de un rato él le dijo: "me voy". Cuando llegó la madre, le preguntó: "¿no saliste?" Ella contestó: "no", entonces le trajo de comer. Al día siguiente fueron nuevamente al monte; vino Luna y le trajo yuca, y al poco rato se fue. Cuando la mamá volvió le preguntó: "¿has comido la yuca?" Pero ella le contestó: "no comí, porque es tierra", y le mostró la yuca verdadera y le dijo: "ahí está la yuca verdadera". Y ahí mismo botaron sus tierras. Al día siguiente, la (mamá) la hizo salir de su encierro y ella vio a Luna que estaba allí sentado, como gente (con aspecto de ser humano). Luna limpió su chacra y sembró yuca. Y toda clase (de cultivos) trajo para sembrar.

Entonces ella (la muchacha) concibió y tuvo un hijo. Y dio (a) luz y nació y su hijo era varón; más tarde se iba a convertir en el Sol. Él creció. Concibió otra vez, y estaba otra vez encinta. Entonces no ha podido dar (a) luz y murió. Le dio una hemorragia muy fuerte y perdió mucha sangre. Y se enojó mucho su mamá, recogió la sangre y se la tiró a Luna en la cara. Por eso ahora se ve la Luna medio negra, porque le ha tirado su suegra con la sangre de su hija".

\subsection{Las manchas de la luna son de barro lanzado a su cara}

Esta explicación del origen de las manchas de la luna se encuentra en una versión procedente del Área Mesoamericana. Se trata de un relato publicado por Pedro Carrasco y que Alcina Franch (1989: 146-147) incluye en una antología de literatura azteca ${ }^{15}$.

El desarrollo narrativo de este relato es el siguiente: Dos hermanos, un niño y una niña [el Sol y la Luna] visitan en el campo a su abuelo. Disgustados porque él no se apresura en prepararles la comida y, además, les exige que lo ayuden, lo matan y lo entierran en un panal 
de abejones. Tras esto, mientras cuecen los frijoles, una voz los acusa de matar y de comerse a su abuelo. Al llegar la abuela, se entera por esta voz del asesinato de su marido y se lanza en persecusión de sus dos nietos. Estos se salvan en una ocasión ocultándose en el hocico de una tuza- pero la abuela los descubre y sigue persiguiéndolos.

En este punto se inicia el pasaje correspondiente al origen de las manchas de la luna, según se aprecia en los fragmentos finales del relato que a continuación citamos:

\footnotetext{
“...la abuela les persiguió otra vez por muchos lugares, hasta que llegaron a la orilla de un río. El muchacho iba siempre adelante y la muchacha atrás. Pensó el niño que podría ser apresado por esperar a su hermana que se atrasaba y cansaba, de modo que mientras esperaba al otro lado del río decidió dejarla. Para que no le estorbara su hermana, se quitó los huaraches para darle un huarachazo en la cara, para manchársela de lodo y que no le viera y no le persiguiera. Ya estaban cerca del fin de la tierra, y así fue como el muchacho subió primero al cielo, donde no le podía seguir la abuelita. Su hermana no tardó en ver después de lavarse algo la cara, de modo que cuando ya se estaba ocultando el hombrecito en el horizonte, pudo subir al espacio la muchacha. Y la mancha que se ve en la Luna es el lodo que le arrojó su hermano, por eso brilla menos que el Sol".
}

Al margen de la diferencia de sexo que presentan los dos hermanos -en este caso, un varón y una mujer- este relato muestra en su desarrollo situaciones y elementos muy similares al texto chatino (véase 3.2), con la diferencia de que en tanto que en la narración chatina el origen de las manchas de la luna se asociaba con el conejo que golpeó la cara de Luna, en ésta se asocia con el barro que el hermano lanza al rostro de su hermana. En todo caso, la relevancia que, en nuestro criterio, posee este último relato radica en el hecho de que constituye hasta la fecha la única versión procedente del Área Mesoamericana que hemos registrado, en la que el origen de las manchas de la luna no se vincula con la tradicional figura del conejo.

\subsection{Las manchas de la luna son mocos que le han lanzado}

Por último, en lo que respecta a las versiones que hemos incluido en el motivo A 751.11 Otras marcas en la luna, cabe hacer mención de un texto procedente del Área Intermedia. Se trata de un relato tunebo (Márquez 1979: 160) que atribuye las marcas del astro a mocos que le han sido lanzados. Este relato, del que citamos a continuación los pasajes pertinentes, es el siguiente:

\footnotetext{
"Una vez que Karasa hizo el firmamento, vio que todo era oscuro y que así nadie podría vivir. Bistoá entonces llamó a Sabursía (la luna) para que viniera a dar luz; ésta llegó, pero no sirvió, porque aunque calentaba lo mismo que el sol, unas veces salía y otras no. Entonces Bistoá tomó yopa... y cuando la hubo tomado, cogió mocos de su nariz, y se los tiró a la luna; por ese motivo tiene manchas y no alumbra. Bistoá entonces le ordenó que solo cuando se fuera Unkárkuba (el sol), alumbrara ella, pues tan perezosa no sirvió...".
}

Finalmente, debemos señalar que el conjunto de versiones que concurren como las distintas explicaciones referentes al origen de las manchas de la luna incluidas en el motivo A 751.11 Otras marcas de la luna, se aprecia en el Mapa 4. 


\section{Mapa 4}

A 751.11 Otras marcas en la luna

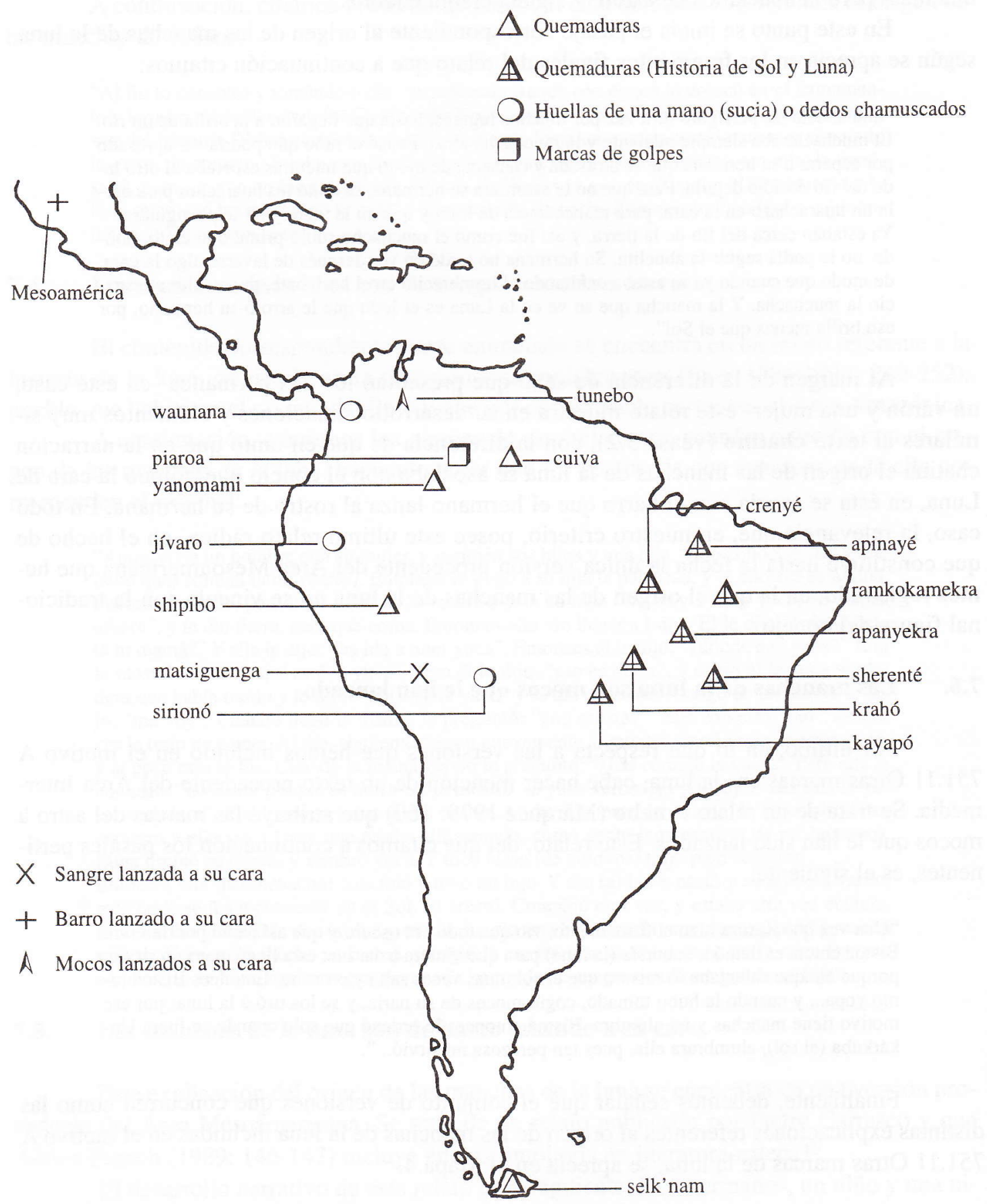




\section{Notas}

1. En los preliminares de nuestra ponencia "Perfiles metodológicos en la investigación de la mitología comparada indoamericana", presentada en el VII Congreso Costarricense de Filología, Linguística y Literatura "Dr. Jack Wilson Kilburn" (San José, octubre de 1997), expusimos los muchos inconvenientes que ofrece el Motif-Index de Stith Thompson para la exacta codificación de la mayor parte de los motivos existentes en la tradición oral de Indoamérica. A su vez, el recurso al que acuden Johannes Wilbert y Karin Simoneau, consistente en agregar los signos " + " o "++" al enunciado de los motivos de Thompson para indicar que los contenidos de las unidades narrativas de los textos indígenas no se corresponden exactamente con la catalogación del Motif-Index, nos parece si bien útil, no satisfactorio ni menos aún definitivo para resolver estos inconvenientes.

2. En nuestras referencias a las Áreas Culturales de América, con excepción de las correspondientes a la América del Norte, en éste, como en trabajos anteriores, hemos seguido las delimitaciones y denominaciones establecidas por Gordon R. Willey (1966 y 1971), quien distingue las siguientes (entre paréntesis, las correspondientes abreviaturas): Área Mesoamericana (MESOAM.), Área Intermedia (A.I.), Área Caribeña (CAR.), Área Amazónica (AM.), Área del Este del Brasil (E.BR.), Área del Chaco (CH.), Área Peruana (PER.), Área Sudandina (SUDAN.), Área Pampeana (PAMP.) y Área Fueguina (FUEG.).

3. En cursiva en el original, al igual que los otros términos que en la cita presentan esta característica.

4. Bierhorst (1988: 33), en lo correspondiente tanto a la versión barasana como a las de los otros pueblos que cita, anota el siguiente contenido de la Historia que denomina "Moon and his sister" ("Luna y su hermana'): "Moon, it is said, used to come to his sister's hammock at night. Wondering who her lover might be, the young woman prepared a pot of black dye (made from the bark of the inga tree), and the next night she painted the man's face. In the morning Moon loocked in a mirror, saw that his face had been blackened, and tried to wash off the dye. But no matter what he did, he could not rid of it."

5. Aun cuando no se trata de pintura, sino de sangre menstrual, el desarrollo del mito en este relato está claramente estructurado de acuerdo con el motivo H 58 Relato de las marcas de la mano, razón por la cual hemos incluido esta versión entre las correspondientes al motivo A 751.5.

6. En relación con las Áreas Culturales de Norteamérica, en éste, como en anteriores trabajos, hemos seguido el criterio de Stith Thompson (1946/1977: 303-309), quien distingue las siguientes (entre paréntesis, las correspondientes abreviaturas): Área Esquimal (ESK.), Área del Río Mackenzie (MACK.), Área del Norte del Pacífico (N.PAC.), Área del Bosque Central (WDL. CENT.), Área del Bosque del Noreste (WDL. N.E.), Área Iroquesa (IROQ.), Área del Plateau (PLAT.), Área de las Planicies (PLNS.), Área de California (CAL.), Área del Sudeste (S.E.) y Área del Sudoeste (S.W.).

7. Bierhorst (1985: 60) señala en la Historia que denomina "Sun Sister and Moon Brother" ("Sol hermana y Luna hermano'), el siguiente contenido: “ A young woman had a lover who came to her bed after the lamps were out. One time she blackened her hands, and when the lamps were relit she saw that it was her own brother who had soot on his back. She accused him, picked up a torch, and ran outside. He pursued her with a dimmer torch and the two rose into sky, become the sun and the moon."

8. El término "paviostos" designa tradicionalmente a los paiutes del norte.

9. La versión gros ventre ofrece en este desarrollo una variante. En ella, es el Sol quien, irritado por las burlas de Luna hacia su esposa, lanza la rana al rostro de su hermano para que ella quedase allí agarrada.

10. Según las indicaciones dadas a Lehmann-Nitsche por su informante, "la casa de las tres viejas" corresponde en la astronomía toba a la constelación formada por las tres estrellas del Cinturón $\delta$, $\varepsilon$ y $\zeta$ Orionis. A su vez, con los tres perros que persiguen al avestruz, se hace referencia, respectivamente, a las estrellas $\alpha$ Centauri, $\beta$ Centauri y $\beta$ Crucis. Tal como se señaló, debe tenerse en cuenta que este relato corresponde íntegramente a la etnoastronomía toba. 
11. En estas referencias bibliográficas, las páginas citadas se refieren a las que en el desarrollo del relato, contienen el episodio en cuestión.

12. Se trata de un roedor acuático de gran tamaño y de apreciada carne (Hydrochoerus capybara).

13. El mito de "la matanza de las mujeres" y la huida al cielo de la vengativa Luna tenían en la tradición cultural selk'nam una enorme importancia. De hecho, desde tales acontecimientos, eran los hombres los que concurrían al hain y los que, con disfraces y máscaras, aterrorizaban a las mujeres, preservando de esta manera el dominio masculino.

En esta perspectiva, los etnógrafos que tuvieron contacto con los últimos selk'nam dan cuenta del temor que suscitaba en las mujeres y del odio que despertaba en los hombres la visión de la luna. Así, Chapman (Id.: 115) recogió un canto nocturno de mujeres en el que éstas entonaban:

\section{Kreeh koosh áixten \\ ('Luna cara quemada') \\ koosh káàten \\ ('cara enfurecida')}

Por otra parte, Gusinde (Id., tomo I, Vol. II: 847) refiere lo que le aconteció con uno de sus informantes en los siguientes términos:

"En una noche de invierno, maravillosamente clara y con luna brillante, acompañé al viejo Tenenesk desde la choza del klóketen hasta el campamento... El viejo no estaba de buen humor... Repentinamente se detuvo. Al cabo de una pequeña pausa, me dijo quedamente: "¡Mira a aquella miserable y traidora mujer allá arriba! Antes había asustado tantas veces a los hombres. Pero un día su propio esposo descubrió sus graves engaños. Con un leño encendido la golpeó y le dio con él en el rostro; las manchas negras y las quemaduras que aún hoy puedes ver en su cara, provienen de esos golpes"... Y lleno de una ira absolutamente real, Tenenesk elevó sus puños contra el brillante disco lunar. Su odio era bien auténtico".

14. En el caso de este personaje, no se trata -como cabría pensar- del Sol. En otros relatos cuivas, la luna es llamada Mayuna o Mañuna, lo cual concuerda con este texto, en tanto que el el sol es denominado Paresi o Sosai. Wilbert y Simoneau (1991: 27 n.3) anotan también el término juameto para designar en cuiva conjuntamente a los dos astros.

15. Ante la imposibilidad de tener acceso al texto de Pedro Carrasco antologado por Alcina Franch, hemos optado por referirlo, sin especificar su origen, al Área Mesoamericana.

\section{Bibliografía}

Alcina Franch, José. 1989. Mitos y literatura azteca. Madrid: Alianza Editorial.

Alexander, Hartley B. 1920/1964. Latin American (XI). En Louis H. Gray (Ed.).

Armellada, Cesáreo y Carmela Bentivenga. 1974. Literaturas indígenas venezolanas. Caracas: Monte Ávila, 1991.

Baer, Gerhard. 1984. Cosmología y shamanismo de los matsiguenga. Quito: Ediciones AbyaYala, 1994.

Bierhorst, John. 1985. The Mythology of North America. New York: William Morrow and Co.

1988. The Mythology of South America. New York: William Morrow and Co.

1990. The Mythology of Mexico and Central America. New York: William Morrow and Co. 
Califano, Mario. 1976-1977. "El mito de la luna de los sirionó de Bolivia Oriental". Scripta Ethnologica (Bs.As.) N4, Parte 2, 100-27.

Califano, Mario y Juan A. Gonzalo. 1995. "La concepción del mundo entre los huachipaeri (harakmbet). El kürednndári (cielo)”. Scripta Ethnologica, Vol. 17, 181-190.

Cárdenas Timoteo, Clara. 1989. Los unaya y su mundo. Perú: Instituto Indigenista Peruano.

Chapin, Mac. 1989. Pab Igala. Historias de la tradición kuna. Quito: Ediciones Abya-Yala.

Chapman, Anne. 1985. Los selk'nam. La vida de los onas. Buenos Aires: Emecé Editores. $4^{\mathrm{a}}$ reimpresión, 1988.

Clark, Ella Elizabeth. 1960. Indian Legends of Canada. Toronto: McLelland and Stewart, 1991.

Correa, Francois. 1997. Los kuwaiwa. Creadores del universo, la sociedad y la cultura. Quito: Ediciones Abya-Yala.

Erdoes, Richard y Alfonso Ortiz. 1984. American Indian Myths and Legends. New York: Pantheon Books.

González Torres, Yolotl. 1991. Diccionario de Mitología y Religión de Mesoamérica. México: Larousse.

Gray, Louis H. (Ed.). 1920. The Mythology of All Races . New York: Cooper Square Publications, 1964.

Gusinde, Martín. 1937. Los indios de Tierra del Fuego (Cuatro Tomos). Buenos Aires: Centro Argentino de Etnología Americana. Primera reimpresión en castellano, 1990.

Instituto Nacional de Cultura (de Panamá) - Instituto Lingüístico de Verano (Eds.). 1980. Literatura Oral Indígena. Primer Seminario Taller de Lingüística Aplicada. Panamá.

Karsten, Rafael. 1935. La vida y la cultura de los shuar. Quito: Ediciones Abya-Yala., 1989.

Krickeberg, Walter. 1928. Mitos y Leyendas de los Aztecas, Incas, Mayas y Muiscas. México: Fondo de Cultura Económica. $3^{\mathrm{a}}$ reimpresión en español, 1985.

Landaburu, Jon y Roberto Pineda. 1984. Tradiciones de la gente del hacha. Mitología de los indios andoques del Amazonas. Yerbabuena: Instituto Caro y Cuervo - UNESCO.

Lehmann-Nitsche, Roberto. 1919. "La cosmogonía según los puelche de la Patagonia". Revista del Museo de la Plata. Vol. 24, Parte 2 (Serie 2, Vol. 12), 182-209. 
1923. "Mitología Sudamericana VI. La astronomía de los tobas". Revista del Museo de la Plata. Vol. III. Serie 3. N²7, 267-285.

Lévi-Strauss, Claude. 1968. Mitológicas III. El origen de las maneras de mesa. México: Siglo Veintiuno Editores, $3^{a}$ edición, 1979.

1971. Mitológicas IV. El hombre desnudo. México: Siglo Veintiuno Editores, $4^{\mathrm{a}}$ edición, 1987.

Lowie, Robert H. 1948. "The Tropical Forests: An introduction”. En Julian H. Steward Ed., 1948 (3), $1-56$.

Márquez, María Elena. 1979. Los tunebo. Medellín: Editorial Copimundo.

Métraux, Alfred. 1948a. "The Guaranî'. En Julius H. Steward Ed., 1948 (3), 69-94.

1948b. "Tribes of Eastern Bolivia and The Madeira Headwaters". En Julian H. Steward Ed., (3), 381-454.

1948c. "Tribes of Eastern Slopes of the Bolivian Andes". En Julian H. Steward Ed., 1948 (3), 465-506.

1967. Religión y Magias indígenas de América del Sur. Madrid: Aguilar, 1973.

Monzón, Arturo. 1945/1948. "Teogonía Trique". Tlalocan Vol. II, 7.

Muñoz de Coronado, Marta Ed. 1989. Cómo surgieron los seres y las cosas. Caracas: CERLALC-UNESCO, $3^{\text {a }}$ ed., 1992.

Pellizzaro, Siro. 1990. Arutam. Mitología Shuar. Quito: Editorial Abya-Yala, 2a ed., 1996.

Reesink, Edwin. 1988. "A Preliminary Note on Kanamari Astronomy”. Scripta Ethnologica (Suplementa) Vol. IX, 121-130.

Rink, Henry. 1875. Cuentos y leyendas esquimales. Madrid: Miraguano Ediciones, 1991.

Rodríguez de Montes, María Luisa. 1981. Nuestra literatura oral en Leticia, Amazonas. Bogotá: Publicaciones del Instituto Caro y Cuervo LVII.

Schultz, Harald. 1950. "Lendas dos indios krahó". Revista do Museu Paulista, N.S., Vol. 14, $49-162$.

Schultze Jena, Leonhard. 1935. Mitos y leyendas de los pipiles de Izalco. San Salvador: Ediciones Cuscatlán, 1977. 
Steward, Julian H. (Ed.). 1948. Handbook of South American Indians. Vol 3. The Tropical Forest Tribes. Washington: Smithsonian Institution. Bureau of American Ethnology. Bulletin 143.

Steward, Julian H. y Alfred Métraux. 1948. "Tribes of the Peruvian and Ecuadorian Montana". En Julius H. Steward Ed., 1948 (3), 535-656.

Stirling, M.W. 1938. Historical and Ethnographical Material of the Jivaro Indians. Washington: Smithsonian Institution. Bureau of American Ethnology. Bulletin 117.

Tagliani, Lino. 1992. Mitología y Cultura Huitoto. Quito: Ediciones Abya-Yala y Centro de Investigaciones Culturales de la Amazonía Ecuatoriana.

Thompson, Eric S. 1970. Historia y religión de los mayas. México: Siglo Veintiuno, $8^{\mathrm{a}}$ ed. en español, 1987.

Thompson, Stith. 1929. Tales of the North American Indians. Bloomington: Indiana University Press, Second Printing, 1967.

1946. The folktale. Berkeley and Los Angeles: University of California Press, 1977.

1955-1958. Motif-Index of Folk Literature. (6 vols.). Bloomington: Indiana University Press.

Velázquez, Ronny. 1993. Mitos de creación de la cuenca del Orinoco. Caracas: Centro Interamericano de Etnomusicología y Folklore. Programa Regional de Desarrollo Cultural de la Organización de Estados Americanos.

Villanes Cairo, Carlos. 1992. Los dioses tutelares de los wankas (Mitos y leyendas peruanos). Madrid: Miraguano Ediciones.

Wilbert, Johannes y Karin Simoneau Eds. 1978. Folk Literature of the Gê Indians. Los Angeles: UCLA Latin American Center Publications (Vol. I).

1984a. Folk Literature of the Gê Indians (Vol. II). Los Angeles: UCLA Latin American Center Publications.

1984b. Folk Literature of the Tehuelche Indians. Los Angeles: UCLA Latin American Center Publications.

1985. Folk Literature of the Chorote Indians. Los Angeles: UCLA Latin American Center Publications. 
1986. Folk Literature of the Guajiro Indians. Los Angeles: UCLA Latin American Center Publications.

1989. Folk Literature of the Caduveo Indians. Los Angeles: UCLA Latin American Center Publications.

1990. Folk Literature of the Yanomami Indians. Los Angeles: UCLA Latin American Center Publications.

1991. Folk Literature of the Cuiva Indians. Los Angeles: UCLA Latin American Center Publications.

Willie, Gordon R. 1966. An Introduction to American Archaeology. Vol. I. North and Middle America. Englewood Cliffs, New Jersey: Prentice-Hall.

1971. An Introduction to American Archaeology. Vol. II. South America. Englewood Cliffs, New Jersey: Prentice-Hall. 